\title{
التفكير المنهجي وضرورته
}

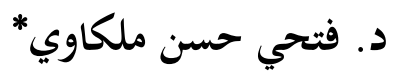

\section{تمهيد}

يبدو أنه لا خلاف على أن التفكير المنهجي ضرورة لنجاح أي عمل، بوصفه يرسم طريق الوصول إلى الغاية المنشودة، وأن الوعي بهذه الضرورة ليس أمرا مستحدثا، بل كان مصاحبا للإنسان عبر تاريخ وعيه، وأن هذا الوعي لم يقتصر على دائرة حضارة دون أخرى، ولا بجال اهتمام أو تخصص معين دون غيره. ومع نرع ذلك فإنّ كثيرا من الناس يفشلون في تحقيق أهدافهم القريبة أو البعيدة؛ لأغم لا يسلكون إليها منهج الوصول، ويصدق هذا على الفرد والجماعة والأمة.

ومع أن كثيرا من المفكرين والباحثين المسلمين قد كتبوا -قديما وحديثا- عن المنهجية وأهميتها وضرورة التفكير المنهجي ومظاهر الخلل في فعاليات العقل المسلم، فإن مظاهر التخلف العديدة في الواقع المعاصر للأمة المسلمة يشهد على كثير من الخلل المنهجي في التفكير وفي البحث وفي التعامل مع الأمور؛ الأمر الذي يستدعي استمرار التنبيه على أهمية الموضوع، ودعوة فئات الأمة بعامة والقيادات الفكرية الواعدة فيها على وجه الخصوص، إلى التمكن من متطلبات التفكير المنهجي ولوازم العمل المنهجي، في ميادينه ومستوياته المختلفة.

وتهدف هذه الورقة إلى بيان دلالات مفهوم المنهجية والمفاهيم ذات العلاقة به، والكشف عن مدى توافر الوعي بأهمية المنهجية والتفكير المنهجي عند فئات المنظرين المعاصرين للفكر الإسلامي والعمل الإسلامي، ورصد بعض صور الخلل المنهجي الشائعة في حياتنا، وتوضيح مسوغات استمرار البحث في موضوع التفكير المنهجي، ومعالجة قضاياه. 
ولهذا البحث صلة، إذ لا يكتمل الحديث في هذا الموضوع دون البحث في تطور دراسات المنهجية، وقضايا إسلامية المنهجية بما في ذلك فكرة وحدة المنهج وتعدده، ومقومات المنهجية الإسلامية وخصائصها. ولعلّ صدر هذه المجلة أن يتسع لمقالات أخرى حول هذا الموضوعات.

\section{المنهج والمنهجية: المفهوم والمصطلح}

كثر استعمال ألفاظ النهج والمنهج والمنهاج، أو(المنهجية والمنهاجية) في الأدبيات المعاصرة، وبخاصة في الدراسات النقدية والفلسفية والتاريخية. والنهج والمنهج والمنهاج في اللغة بمعنى واحد وكلها تشترك في إشارتا إلى الطريق، المستقيم، الواضح، الذي يوصل إلى الغاية بسهولة ويسر، كما تتضمن معنى الإسراع في السير في الطريق لوضوحها أو في إنجاز العمل لوضوح طريقته.

و يأتي أصل هذه الألفاظ لغة من الجذر فج وأفْج بمعنى وضح واستبان وصار فجا واضحا بيّنا. جاء في التنزيل الحكيم قوله تعالى: "لكل جعلنا منكم شرعة ومنهاجا" (المائدة: 48)، وقال يزيد بن الخذاق

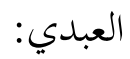

$$
\text { سبلُ المكارم والهُدى تُعْدِبوي }
$$

ولقد أضاء لك الطريقُ وأفْجت

أي تُعِينُ وتُقُوِي، والنهج: الطريق المستقيم، والمنهاج: الطريق المستمر.

وطريق ناهجة أي واضحة، ويف حديث ابن عباس، رضي الله عنه: "لم يمت رسول الله صلى الله عليه وسلم حتى ترككم على طريق ناهجه". وهِِج فْجا وأْهَج إذا انبهر أي تواتر نفسُه من شدة الحركة، وفي حديث عائشة فقادني وإنيّ لأهج، وفي الحديث: أنّه رأى رجلا ينهج أي يربو من السِّمن ويلهث. 1 وبين المنهاج والمقصد علاقة وثيقة، يقول السبكي في شرحه لمنهاج البيضاوي: "المنهاج: الطريق جعل علما على هذا الكتاب. والوصول إلى الشئ إنما يكون عند انتهاء طريقه، فقوله (أي البيضاوي) منهاج

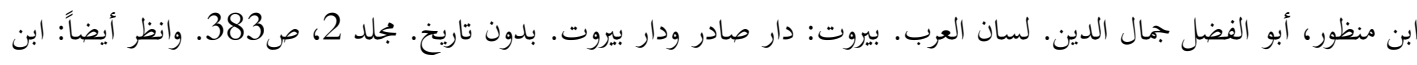

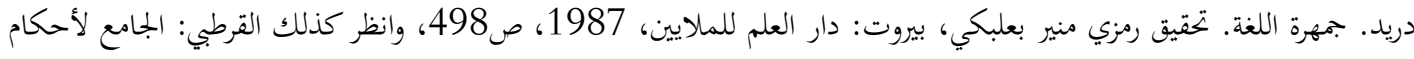

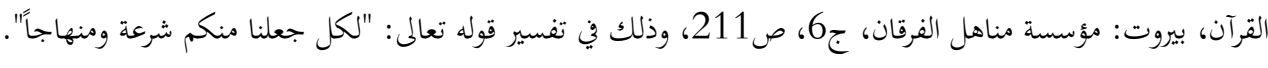


الوصول معناه الطريق الذي يتوصل فيها إلى الوصول إلى علم الأصول، كما تقول: طريق مكة، أي المتوصل فيها إلى مكة، فليس الوصول فيه وركنّه غايته."2

وترد هذه الألفاظ في كثير من الأحيان بصورة مترادفة، فيستعمل أحدها في موقع الآخر دون تغيير في الدلالة. كما تستعمل بدلالات متعددة؛ فيقال المنهج الإسلامي أو المنهج الماركسي للإشارة إلى النظام المعريف أو الرؤية الكلية -الفلسفة- للكون والحياة والإنسان؛ ويقال: المنهج التربوي في الإسلام ويقصد به علم متخصص من العلوم؛ ويقال: منهج الشافعي في الأصول أو منهج المعتزلة في الكلام، ويقصد به المذهب أو المدرسة الفكرية الخاصة بباحث أو مفكر أو عالم، أو بفئة من المفكرين أو العلماء؛ ويقال: كان المنهج المستخدم في الدراسة هو المنهج التاريخي أو المنهج التجريبي، ويقصد به نوع البحث الذي يتضمن طرقا وإجراءات محددة. والمنهج والمنهاج الدراسي هو خطّة الدراسة، أي مجموعة المواد والخبرات التعليمية الموضوعة لتحقيق أهداف التربية. والمنهج العلمي هو الطريقة العلمية في البحث التي تقوم على الملاحظة ووضع الفرضيات واختبارها والتوصل إلى النتائج وتعميمها. والمنهجية Methodism هي فلسفة الإحياء الديني في القرن الثامن عشر في أوروبا وبدأت في جامعة أكسفورد حيث تكون دراسة الدين والدعوة إليه على أسس منهجية. ولا يزال أتباعها يأخذون اسم Methodists أي المنهجيين. 3

والمنهجية مصدر صناعي للمنهج. ويختلف في معناه عن الاسم المنسوب الناتج عن إضافة ياء النسبة وتاء التأنيث في أن المراد أمر آخر غير الوصف، حين نقول: يقوم الباحث بعمله بطريقة منهجية، أي منظمة غير عشوائية؛ بل يفيد المصدر الصناعي مجموعة الصفات الخاصة باللفظ، ويكون المستفاد به كالمستفاد بالمصدر في دلالته المعنوية، حين نقول يتميز الباحث بمنهجية التفكير كما نقول يتميّز بسلامة التفكير أو صحته، وتكون بمعنى؛ يتميّز الباحث بكون تفكيره منهجيا. وقد يشتبه المنسوب بالمصدر الصناعي في مثل: يفكر بمنهجية؛ إذ يستقيم لنا تقدير لفظ محذوف، يفكر بطريقة منهجية، كما في عرض الدنيا؛ أي عرض الحياة الدنيا، كما يستقيم لنا لفظ تأويل المصدر: يفكر بوضوح،... وهكذا.

2 2 2

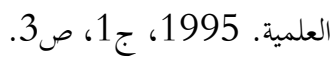

3 
ويشبه المصدر الصناعي أن يكون صيغة حادثة، دعت إليها دواعي التوسع في مواجهة حاجات التعبير وقد أكثر منه المولدون عند استخدام المصطلحات وبخاصة في أثناء ترجمة العلوم وغيرها إلى العربية، وأصبح متعارفا على نطاق واسع -أن يستفاد بالمصدر الصناعي في مثل: منهجية التفكير: كون التفكير منهجيا. وهو فرق لطيف يلحظ بين المراد بالمشتق (والمنسوب) والمصدر، وقد نجم عن هذا الفرق فرق آخر في سلوك الصيغتين نحويا؛ إذ يتمايز اللفظان بوقوع المنسوب وصفا في الغالب: طريقة منهجية، ووقوع المصدر الصناعي مضافا في الغالب: منهجية التفكير. 4

ويقابل لفظ المنهجية لفظ Methodology في اللغة الإنجليزية، وتعني "العلم الذي يدرس الطرق"، أو "ذلك الفرع من المنطق الذي يحلل المبادئ والاجراءات التي تحكم البحث والاستقصاء في مجال معريف معين"، أو "تلك الأسس النظرية لمذهب فلسفي معين، أي الافتراضات والمعطيات والمفاهيم الأساسية

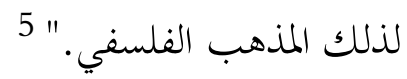

وهكذا يظهر أن المنهجية في اللغة الإنجليزية هي مصطلح على "علم" من العلوم المحدثة، وهذا العلم هو علم الطرق أو علم المناهج ويتعلق بجميع العلوم، لكنه أشد ارتباطا بتاريخ العلوم، وفلسفة العلوم، ونظرية المعرفة على وجه الخصوص، وقد يكون المصطلح جزءا من كل علم أو فرعا من أي مجال معريف (الفيزياء، التاريخ،...) يدرس منطق ذلك المجال المعرين، وبنيته، وأساليب تحصيل المعرفة والبحث فيه؛ فيُقال مثلا منهجية علم التاريخ...

$$
4
$$

5 Agnes, M. \& Guralnik, D. (Eds) Webster's New World College Dictionary. 4th. Ed. Foster City, CA. Webster's New World, 2001, P.906.

$$
\text { ويكن ملاحظة نفس المعنى تقريباً في: }
$$

Abate, Frank (Ed.) DK Illustrated Oxford Dictionary, New York: Oxford University Press. 1998, p. 515. 
وبهذه الدلالة يتحدد معنى المنهج Method بطرق البحث وإجراءاته في مجال معرفي، بينما يتحدد معنى المنهجية Methodology بالعلم الذي يدرس هذه الطرق والإجراءات. ويتولى تحديد الصفات والخصائص التي تتميز بها طرق البحث كالقصد والوضوح والاستقامة. 6 وتعطي المعاجم العربية الحديثة لفظ المنهجية دلالات مختلفة تتراوح ما بين الدلالات التي يعطيها معجم وبسترالمشار إليه أعلاه لهذه اللفظة، والدلالات التي يعطيها للفظة المنهج. وأكثر هذه المعاجم تعيد المعنى الذي يختاره صاحب المعجم إلى واحد أو أكثر من المعاجم الأجنبية التي يترجم عنها.

فالمعجم الفلسفي الذي أصدره مجمع اللغة العربية بالقاهرة يحدد معنى المنهجية بأها: فرع من فروع المنطق يدرس المنهج بوجه عام ويدرس المناهج الخاصة للعلوم المختلفة، 7 والموسوعة الفلسفية لعبد الرحمن بدوي توحد بين علم المناهج وبين علم المنطق أي قواعد التفكير في العلوم الجزئية. 8 وقد استعمل المؤلفون هذه الألفاظ الثلاثة باصطلاحات مختلفة لا تختلف عن ذلك، ولكنها قد تضيف دلالة محددة على جانب مخصوص أو إطار فكري عام وقد لا يكون ثمة فائدة في تتبع هذه الاستعمالات والموازنة بينها. وأكثر من استعملها من المؤلفين العرب حاول أن يجمع في استعماله دلالة اللفظ في التراث العربي الإسلامي وترجمات استعمالاتما في اللغتين الإنجليزية أو الفرنسية، وبخاصة في المعاجم المتخصصة في هاتين اللغتين. وبالإضافة إلى الدلالات العديدة التي لا تزال تعطي للفظ المنهج والمنهاج ما بين المعنى المحدود المخصوص والإطار الفكري العام وما بينهما، فإن هذا المصطلح قد استعمل للدلالة على جانب من فلسفة العلم الذي يتعلق بطرق النفكير والقواعد العامة التي يستعملها الإنسان في البحث عن الحقيقة في العلوم وهّيمن على سير العقل وتحديد عملياته حتى يصل إلى نتيجة معلومة. 9 وما أصبح يطلق عليه علم المنهاج (Methodology) وهو يوازي إلى حد كبير ما عرف في تاريخ العلم والفلسفة سواء في الحضارة اليونانية القديمة أو في الحضارة العربية الإسلامية، بـ "علم المنطق" أو ما يوازيه من مصطلحات

6 6

$$
\begin{aligned}
& 77
\end{aligned}
$$

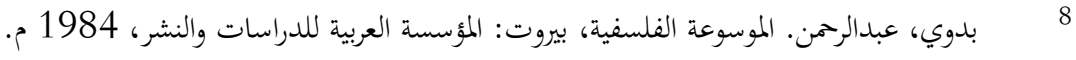

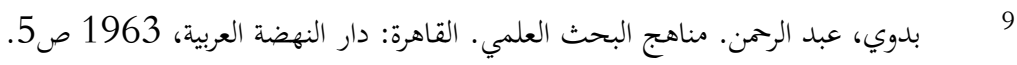


إسلامية مثل أصول الفقه عند الشافعي أو معيار العلم أو معيار النظر عند الغزالي. "قولمم إن المنطقيات لابد من إحكامها هو صحيح ولكن المنطق ليس مخصوصا بهم وإنما هو الأصل الذي نسمّيه في فن الكلام "كتاب النظر" فغيروا عباراته إلى المنطق تويلا. وقد نسميه "كتاب الجدل"، وقد نسميه "مدارك العقول." 10 يتضح من ذلك أن مصطلح المنهجية يتداخل مع مصطلح المنهج أو المنهاج؛ ومع أساليب البحث عن المعرفة في حقل من الحقول ومع المنطق باعتباره موضوعا فلسفيا، ومع نظرية المعرفة والابستمولوجيا باعتبارها فرعا من فروع الفلسفة وعلما من علومها. لكن هذه المصطلحات جميعها تستخدم في حقل المعرفة، والمعرفة تشمل الوجود غيبا وشهودا، وتشمل الناس أفرادا وجماعات، لكنها في النهاية معرفة إنسانية محدودة بحدود الإنسان في قدراته على الفهم والإدراك.

ولما كانت المعرفة في ميادينها المتعددة هي بجال عمل المنهجية، فإننا نتوقع أن تضع المنهجية بجموعة من الافتراضات حول المعرفة. كما نتوقع أن تشتمل هذه الافتراضات على ثلاثة بجالات، 11 افتراضات تتعلق بالإنسان العارف أو الباحث مثل: الإيجابية والانفتاحية والأمانة والشمول في النظر، و...، وافتراضات تتعلق بموضوع المعرفة البحثية، مثل: قابلية الموضوع للمعرفة، وقابلية الموضوع لتكرار معرفته من الآخرين وقابلية الموضوع للاختبار، و....، وافتراضات تتعلق بأدوات المعرفة، مثل: الاعتماد على البيّنة، والاعتماد على لئل قواعد العقل في التعامل مع البيّنة ومحاكمة البيّنات وأسلوب التعاطي معها وتقويمها في ضوء صلاحيتها

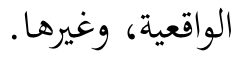

يتضح من ذلك أيضا أن بجال عمل المنهجية يشمل حقول المعرفة في تصنيفاتما المختلفة: النقلية والعقلية، أو الشرعية والطبيعية والاجتماعية، أو أية تصنيفات أخرى. وقد ارتبط مصطلح منهج ومناهج ومنهجية بقضايا البحث العلمي وإجراءاته وأنواعه، كما ارتبطت الدلالات والمعاني الخاصة بهذا المصطلح بعناوين البحوث وأنواعها والفئات التي يمكن أن تصنّف فيها البحوث، حسب معايير التصنيف المختلفة.

$$
\begin{aligned}
& 10
\end{aligned}
$$

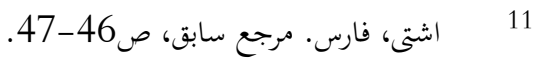


ومن هذه الدلالات ما يتعلق بالحركة داخل حدود العمل البحثي من أدوات وطرق تستخدم في جمع بيانات البحوث من اختبارات واستبانات وأساليب مسحية ومقابلات وغيرها. ونحن هنا لسنا بصدد ذلك، ولكننا بصدد التفكير والتأمل في قضايا ما وراء المنهج 12 وهي قضايا أقرب إلى ما يسمى فلسفة البحث أو فلسفة العلم بعامة، أو فلسفة المنهج. وهذه هي الدلالة التي نودّ أن نعطيها لمصطلح المنهجية.

وإذا كانت المنهجية تحدد القواعد العامة لطريقة التفكير فإنها تتضمن بالضرورة التصور والتخطيط

المسبق والرؤية الكلية للعناصر، كما ينبثق عنها مناهج تفصيلية تحدد طريقة الوصول إلى أهداف محددة من خلال إجراءات عملية وأساليب تنفيذية. ولا نتصور عملا وتنفيذا لأمر من الأمور لا يسبقه تصوّر وتفكير مسبق.

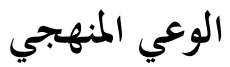

إذا أرادت الأمة المسلمة أن تستعيد عزها وترتقي إلى مبلغ أمانتها وتتصدر قافلة الحضارة، فإنه من الضروري أن يتوافر لديها الوعي المنهجي وتتمكن من تطويره. ولمها كانت المنهجية هي "علم" بيان الطريق، فإن الوعي المنهجي ضرورة لازمة لأنّ "الطريق قد يطول وتعتريه الكثير من العوارض وتتعدد فيه المنازل، فما بين المنحنيات التي قد تخزج السالك عن سبيله، وما بين المعارج التي قد ترتفع به لتفسح الآفاق، تكثر المزالق والمهلكات التي تتعثر إزاءها الخطوات، وعندها تكون المنهجية مصدرا لابتغاء الرشد..." 13

ويتطلب الوعي المنهجي بالضرورة وضوحا في خطوات البناء المنهجي، وفي سبل السعي للانتقال من الغاية إلى الأخذ بالأسباب وتنفيذ البرامج لتحقيقها، ويرتبط هذا الوضوح المطلوب بتوافر قدرات معينة، منها مثلا التمييز بين عملية بناء المفاهيم وعملية بناء الأطر المرجعية للتحقق من فعالية تلك المفاهيم ولتحقيق غاية المنهجية. وقد أطلقت منى أبو الفضل على هذا التمييز مصطلح "العقدة المنهجية"14 ثم أشارت إلى أننا لا

$$
12
$$

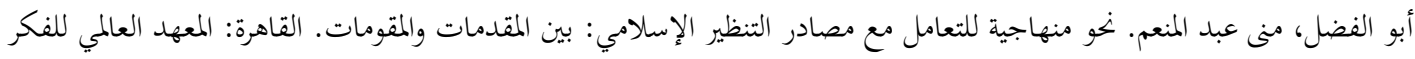

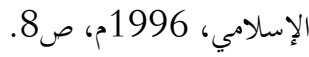

المرجع السابق، ص11 
نستطيع تجاوز هذه العقدة المنهجية وارتياد الوثبة الحضارية المرتقبة ما لم يتحقق الوعي المنهجي اللازم للتعامل مع مصادر التنظير الإسلامية.

وأول المقومات الإسلامية في هذه المنهجية ما يتعلق بمنهج التعامل مع القرآن الكريم. وتلاحظ منى أبو الفضل أن النماذج التي تنطلق في تعاملها مع الخطاب القرآي من منطلق شمولي، وتلك التي تسعى لتنزيل ما تستفيده من النظرة الكلية على الواقع الاجتماعي جملة، وفي بجال المعرفة المتخصصة بسنن وابتحهات هذا الواقع، على وجه الخصوص، إنما هي من القلة بمكان، ولا تزال الجهود الفردية المتفرقة لا ترقى بعد لأن تقدم الدفعة التي من شأها أن تحدث تغييرا نوعيا في المناخ المعرفي السائد، والذي يتسم بالفوضى والتخبط والسطحية من جانب، وباستمرار فيض المؤثرات الفكرية الوافدة من جانب آخر. 15

ولعل من المفيد في هذا المقام الإشارة باقتضاب إلى علاقة الوعي المنهجي بآليات التفكير الإنساني وصوره ومستوياته. يقولون إن العلم -أي علم- هو بمنهجه لا بموضوعه، أو على الأقل بمنهجه وموضوعه معا، فاكتساب العلم وحصول المعرفة والإدراك عند الإنسان "عملية" فاعلة ومنفعلة، إذ تتأثر منجهية الباحث بعقليته ونفسيته وسائر المؤثرات التي تشكل شخصيته، وتشترك في الوقت نفسه في صياغة الوعي العام في المجتمع وأنماطه الثقافية التي تحدد بدورها قضايا البحث العلمي وأولوياته ومعاييره.

وتؤثر منهجية التفكير في وعي الإنسان بالواقع؛ فعندما يفكر الإنسان ويحاول نقل الواقع كما يدركه، فإنه لا ينقل الواقع ذاته، وإنما يقترب منه بقدر ما يستخدم من منهجية مناسبة. 16 وتتعلق هذه المحاولة بنتيجة التفاعل بين ثلاثة عناصر الأول هو المدركات القبلية المستقرة في ذهن الإنسان، وتتمثل عادة بمجموعة المبادئ والقيم التي تتصل بالفطرة أو تأتي من النظم والظروف الاجتماعية، والثاني هو الأدوات التي يستخدمها والعمليات العقلية والشعورية وملكات الحدس والخيال والإرادة التي يمارسها، والثالث هو الحقائق الموضوعية المرتبطة بالواقع؛ أي خصائصه الكمية والكيفية، وعلاقاته بما حوله. ويتم التفاعل بين هذه العناصر في العقل الإنساتي الذي يقوم بتنظيمها ضمن ما يسمى بالخبرة الإنسانية، وهذه الخبرة هي المضمون الذي

$$
15
$$

عارف، نصر عمدا. (مرر) قضايا المنهجية في العلوم الإسلامية والاجتماعية. أعمال مؤتمر المنهجية المنعقد في الجزائر عام 1989.

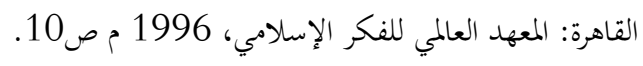


يستخدمه الوعي الإنساني لفهم الواقع الطبيعي والاجتماعي، وإدراك موضوعاته وظواهره، وتفسيرها وبيان دلالاتما وإمكانات توظيفها في الفهم والسلوك. ومع ذلك فإن وعي الفرد الإنساني قد يكون وعيا مزيفا؛ لأن الواقع الاجتماعي وظروفه وإرغاماته يفرض على الأفراد قيودا وشروطا تتطلب التماهي مع الثقافة السائدة والوعي (أو اللاوعي) الجمعي، وهذه الظاهرة هي أحد أسباب الركود والتوقف عن العطاء الفكري والحضاري ل المجتمعات.

ومع ذلك يظل في كل مجتمع قليل من الأفراد لديهم إرادة التفوق والإبداع ويمارسون الحرية في الاستقلال والتميز، فيتجاوز وعْيُهم الوعي السائد عند الناس عامّة، لأفم يفهمون الواقع بصورة جديدة وينظمون خبراقم حوله على نخو ريادي، وقد يبشرون بفكر جديد، ومنهج جديد، وينشرون نوعا جديدا من الوعي. وربما يكثر أتباعهم، وتوضع أفكارهم موضع العمل، فتتحقق النهضة ويحصل التجديد.

وقد تمثل الوعي بتخلف واقع الأمة وحاجتها إلى النهضة في كتابات الكثيرين من دعاة الإصلاح منذ قرن ونصف، ولكن هذا الوعي بدا مرتبكا مشتتا، موزعا على منهجيات أحادية قاصرة؛ فمنهم من دعا إلى منهج سلفي لحمته تقديس الماضي والثناء على السلف، وسداه القطيعة مع مناهج الغربين وبيان عوراقم ومثالب إنجازاتم، حتى إذا التفتوا إلى نصيبهم من الدنيا، أرسلوا أبناءهم للتعلم على مناهج الغربيين، ولحقوا بهم للاستمتاع بمنجزات هذه المناهج، وملؤوا بهذه المنجزات بيوقم ومكاتبهم وشوارعهم؛ ومنهم من دعا إلى إلى منهج حديث أعمل فيه فنون جلد الذات، والاختيار الانتقائي من التاريخ الإسلامي الذي يظهر من الوقائع والنماذج ما يجعله مبررا لمدم التاريخ كله والقطيعة معه، أما الغرب فإن له من الفضل وفيه من العبقرية ما

يؤهله للسيادة والقيادة. 17

ولعلّ أزمة الوعي الإسلامي التي مثلتها تلك المناهج تعمقت في نفوس الكثيرين من الناس، أولا لأن دعاقما من الطرفين كانوا في أكثر الأحيان من أولى الأمر في الأمة، سواء على مستوى الحكم أو على مستوى التوجيه. كما تعمقت أزمة الوعي هذه نتيجة الإحباط واليأس الذي أناخ بكلكله على كثير من الناس نتيجة

كار، عبد الكريم. بتحيد الوعي. سلسلة الرحلة إلى الذات رقم 2. دمشق: دار القلم. 2000م، الفصل الأول بعنوان حول شؤون

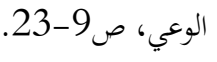


الهزائم العسكرية والسياسية المتتالية، وسقوط القيادات والشعارات التي كانت تمثل أفق الأمل. ولكنّ في بعض الشر خيرا أحيانا، فإن الهزائم المنكرة كثيرا ما كانت عاملا من عوامل "عودة الوعي" حتى عند من كانوا يظنون أفم "قادة الوعي" والفكر والثقافة في أمّهم. 18

وأخطر أشكال التزييف أو الارتباك في الوعي هو ما يتعلق بالمنهج، فإن افتقاد الوعي المنهجي "يجعلنا ننحرف بالمنهاجية ووظيفتها، بل قد يتطرق بنا الأمر إلى الاطلاق على بعض منها اسم المنهج، رغم أها لا تمت لهذه التسمية بصلة؛ فالمنهاجية في حقيقتها تعدّ مصدرا لابتغاء الرشد وتحقيق الوعي، فإذا كان المنهج هو الطريق الموصل إلى المقصد فإنه يفرض علم الطريق وبيان الوصول، وبقدر صحة منطلقاته وسلامة وجهته يكون قيامه مقام المرشد الأمين الذي يبين معالم الطريق."

وعلى أية حال فإن الإحساس بالحاجة إلى المنهج والتفكير المنهجي - كما يبدو - أخذ يتزايد خلال نصف القرن الماضي في مختلف أنحاء العالم الإسلامي، حتى أصبح المنهج هاجسا يشغل العلماء والمتخصصين في مختلف فروع المعرفة، وفي أوساط الفكر والدعوة والحركة على حد سواء. فالدعاة يقدمون دراسات منهجية في علم الدعوة، 20 ويدعون إلى سلوك منهج محدد في الدعوة هو منهج الأنبياء؛ 21 وإذا اختار أحدهم نصوصا معينة من كتابات السلف، فإنه ربما يختار "الكلمات المنهجية"22 عنوانا لكتابه؛ وإذا جمع أحدهم

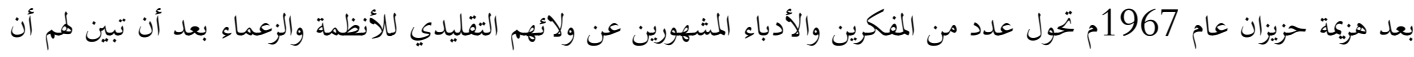
القيادات السياسية قد ضللت الجماهير كما ضللت القيادات الثقافية والفكرية حتى كأفا كانت تعيث حالة فقدان الوعي، وكانت الهزيمة سبباً في "عودة الوعي"، وهو عنوان كتاب ألّله توفيق الحكيم ونشرته دار المعارف بالقاهرة عام 1972م، ومثله قصائد نزار قباني بعد المزيمة المذكورة. عبد الفتاح، سيف الدين. حول المنهجية الإسلامية: مقدمات وتطبيقات. ورقة قدمت في دورة المنهجية الإسلامية الثالثة في المعهد 19

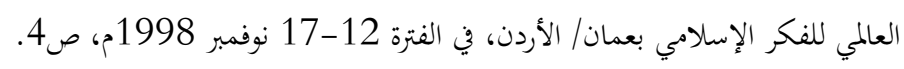

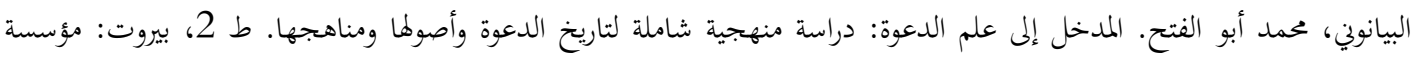

$$
21
$$

22 22 
مجموعة من المقالات الصحفية التي سبق نشرها لتنشر في كتاب، فقد يختار "مقالات في المنهج"23 عنوانا

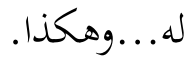

وفي المجال العلمي المتخصص "الأكاديمي" يتم التحدث عن علم الأصول بوصفه منهج بحث ومعرفة24 وتظهر فيه الحاجة للبحث في العلم وبحديده من أجل معالجة أزمة المنهج أو إشكالية المنهج المعاصرة. وعندما يتم الحديث عن العقيدة الإسلامية ينصرف الاهتمام إلى مناهج البحث فيها، باعتبار ذلك "دراسة لمناهج الفكر الإسلامي المعاصر وللعناصر المنهجية في دراسة أصول الدين"، ذلك أن هذا الدين قد جعله الله منهاجا مستقيما مشتملا على مسائل العقيدة والعبادة والأخلاق والتشريعات، وهذه العناصر في مجموعها هي التي تمثل "المنهاج الإسلامي" الذي استقام عليه الرعيل الأول، ثم خلف من بعدهم خلوف جعلوا هذا المنهاج عضين؛ ما بين مسائل كلامية فلسفية، أو مشاعر وجدانية صوفيه، أو عبادات بتزيئية جافة..الأمر الذي اقتضي ظهور المصلحين المجددين الذي عملوا على "إعادة الترابط إلى بنية المنهاج الإسلامي ورفض الوضع التجزيئي."25

وإذا تطرق الحديث إلى المنهج العملي للإسلام بخصائصة وأركانه فسنجد مع يوسف القرضاوي أنه يتجسد في السنة النبوية؛ لأفها التفسير العملي للقرآن "فقد كان النبيّ صلى الله عليه وسلم هو القرآن مفسّرا، والإسلام مجسّما.. ومن واجب المسلمين أن يعرفوا هذا المنهاج النبوي المفصل بما فيه من خصائص الشمول والتكامل والتوازن والتيسير، ويعرفوا بالتالي كيف يحسنون فهم السنة والتعامل معها.." وإذا كانت "أزمة المسلمين الأولى في هذا العصر هي أزمة فكر" فإن "أوضح ما تتمثل فيه أزمة الفكر هو أزمة فهم السنة النبوية والتعامل معها، وخصوصا في بعض تيارات الصحوة الإسلامية.. فكثيرا ما أوتي هؤلاء من جهة سوء

2323

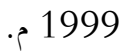

العلواني، طه جابر. أصول الفقه الإسلامي: منهج بحث ومعرفة. هيرندن، فيرجينيا: المعهد العلمي للفكر الإسلامي. ط2، 1995، 24

الزنيدي، عبد الرمن بن زيد. مناهج البحث في العقيدة الإسلامية في العصر الحاضر: دراسة ملناهج الفكر الإسلامي المعاصر ولمعناصر

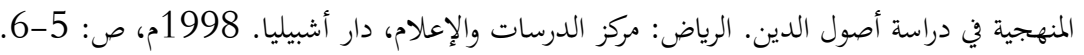


فهمهم للسنة المطهرة."26 ويرصد عبد الجبار سعيد عددا من مظاهر الخنل في منهجية التعامل مع السنة النبوية.27

وفي الدراسات التاريخية ما تزال قضية المنهجية منذ عهد ابن خلدون وحتى الآن ملتبسة على كثير من ولجوا عالمها متوكئن على النصوص التي نقلها الأوائل بوصفها حقائق مسلمة، مما أوقع المؤرخين في أخطاء منهجية، مثلهم في ذلك مثل أولئك الذين حاولوا التخلي عن هذا المنهج إلى منهج المستشرقين الذين -وإن كان لمم بعض الفضل في جوانب محددة- انطلقوا من مصالح الاستعمار، وعقدة التفوق الغربي مما جعلهم يكتبون التاريخ "من وراء الجدار الزجاجي، فلم يمسكوا.. بالخيوط الأساسية التي حركت أحداثه وجهلوا بالتالي خصوصية الإسلام في عالمه وزمانه الخاصين.." "28

وقضايا الفكر الإسلامي المعاصر تحتاج إلى محاولة يتكامل فيها النظر في منهجية الفكر الإسلامية بيانا للعيوب واقتراحا للإصلاح، وتوجيه الحوار حول الجانب المنهجي في الفكر الإسلامي من أهم مهمات الفكر الإسلامي اليوم.."وهل أزمة المسلمين منذ زمن إلاّ أزمة منهجية تفكير في أساسها؟"29

وفي بجال الأدب والنقد نجد من يتحدث عن تزايد الإحساس بالوعي المنهجي حتى أصبح البحث عن المنهج الإسلامي في النقد الأدبي من القضايا التي تحتل الأولوية، بسبب عدم ملاءمة المناهج الغربية في التعامل مع التجربة الإسلامية المعاصرة في الإبداع الأدبي، ولذلك لا بد من منهج إسلامي بديل في النقد الأدبي يعكس شخصية المسلم وتطلعاته المنبثقة من عقيدته وتصوراته لتحديد آفاق هذا المنهج وبحريب أدواته وتوضيح مقوماته حتى تكتمل صورته.. وقد أصبحت هذه الدعوة اليوم ضرورة ملحة أكثر من أي وقت مضى لأن المناهج الأجنبية تزداد رسوخا بفضل ما لها من بريق وجاذبية وما يصاحبها من دعاية، ولأن "العالم

26 2 القرضاوي، يوسف. كيف نتعامل مع السنة النبوية: معالم وضوابط. هيرندن: المعهد العالمي للفكر الإسلامي، والرياض: مكتبة المؤيد،

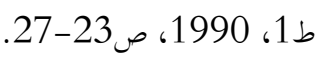

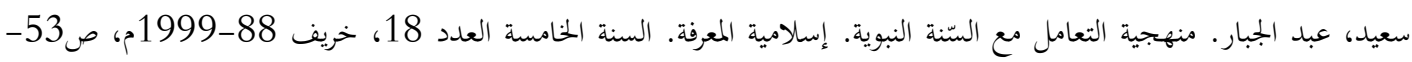

بيضون، إبراهيم. الكتابة التاريخية الإسلامية: بين الطريقة والمنهج. المعهد: بجلة ثقافية فصلية يصدرها معهد الدراسات العربية والإسلامية

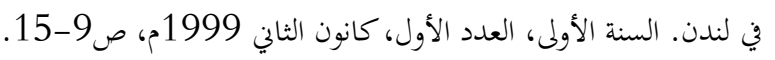

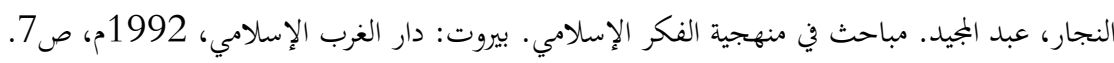


من حولنا قد تقدم في مناهج البحث والتفكير، كما تقدم في مناهج العمل والتطبيق ولكن كثيرا من الممارسات التي تشهدها الأمة الإسلامية توحي بأهما قعدت عن اللحاق بالركب والاستسلام للاستهلاك المنهجي والمادي اعتمادا على مناهج غير نابعة من صميم حضارقا. ولا بد من دراسة هذه المناهج المستوردة فنستفيد من إيجابياتما التي لا تتعارض مع رؤيتنا الحضارية وتصورنا الإسلامي، وفي الوقت نفسه نسعى إلى تأصيل منهجنا المتميز الذي يأخذ ويعطي في الحدود التي تحافظ على مقوماته وخصائصه. "30

وفي مجال النقد الأدبي والدراسات المصطلحية، يبين البوشيخي أن "مشكلة المنهج هي مشكلة أمتنا الأولى ولن يتم تحليقنا العلمي ولا الحضاري إلا بعد الاهتداء في المنهج للتي هي أقوم - "اهدنا الصراط المستقيم". فينبغي أن نخرص على استقامة المنهج في كل شيء. وأن يكون الجها المبذول في تقويم المنهج مكافئا لهذه الأهمية، وما العلم إلاّ تلك الصفة التي تقوم بالإنسان نتيجة منهج معين في التعلم والتعليم، تجعله قادرا على علم ما لم يُعلم.. ومع أن الاستيعاب جزء من المنهج، ولكن المهم هو ما بعد ذلك تحليل وتعليل وتركيب."

وفي المجال الفكري يؤكد طه عبد الرممن حاجة اليقظة الدينية المعاصرة في العالم الإسلامي إلى "السند الفكري"، وذلك بدعم التجربة الإيمانية بأحدث المناهج العقلية وأقواها وتأسيسها عليها، وأن القصور في هذا الباب هو الذي جعل هذه اليقظة تنحو في ابتحات أطمعت الخصوم في التعرض لها والإساءة إليها "ولو أن أهل اليقظة حصّلوا ملكة منهجية عمِل التغلغل في تحربة الإيمان على فتح أبوابها، لتمكّنوا من إقامة فكر إسلامي جديد يحصّن هذه اليقظة.."32

ويصل الوعي المنهجي وتقدير مدى الحاجة إلى التفكير المنهجي عند عبد الحميد أبو سليمان حدّ المطالبة بإنشاء "علم منهجي" قادر على "حل معضلات التربية".. "ودراسة قضاياها دراسة علمية منظمة

30 3 الغزيوي، علي. مدخل إلى المنهج الإسلامي في النقد الأدبي. (سلسلة كتاب دعوة الحق، العدد السادس). الخمدية، المغرب: وزارة

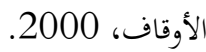
31 3 البوشيخي، الشاهد. مشكلة المنهج في دراسة مصطلح النقد العربي القديع. المسلم المعاصر. العدد 14، يناير-أبريل 1990م،

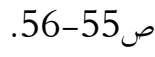
عبد الرمن، طه. العمل الديني وبحديد العقل. بيروت: المركز الثقافي العربي، 1997م، ص9-10. 
مستمرة دون التأملات الفكرية العشوائية المحدودة". وآية ذلك أن إصلاح حال الأمة لا يكون إلا طريق إعادة بناء الأجيال الجديدة ابتداء من التنشئة الأسرية ومرورا بالمؤسسات التربوية، وهي نظرة في منهجية الإصلاح والتغيير كما هي نظرة في نشأة العلم اللازم لهذا الإصلاح -وهو التربية - وفهم هذه العلم الذي يصفه بـ" الدراسة العلمية المنظمة المستمرة" المتميزة عن "التأملات الفكرية العشوائية المحدودة". 33 ويرى أبو سليمان أن ثمة شروطا ثلاثة للنهضة والإصلاح، أوّلها قوة البناء النفسي والشجاعة النفسية، وثانيها سلامة منهج التفكير وتفوّقه، وثالثها وضوح الرؤية الحضارية التي تقصد عموم الخير للخلق كافّة. وعندما ينظر أبو سليمان في أثر فقدان هذه الشروط، نجده يضع منهجية التفكير في المقدمة فقد "أدى الانفصام التاريخي بين القيادة الفكرية والقيادة السياسية في كيان الأمة.. إلى خلل المنهج، وأدّى خلل المنهج إلى تدمير القوة النفسية وإلى فقدان الرؤية الحضارية.."34

وإذا كانت قضية المنهج قضية فكرية في المقام الأول فإن الاهتمام بها لم يقتصر على المفكرين والباحثين في المجال الفلسفي النظري، بل إن المنظرين للحركة الإسلامية من رجال الفكر على وجه

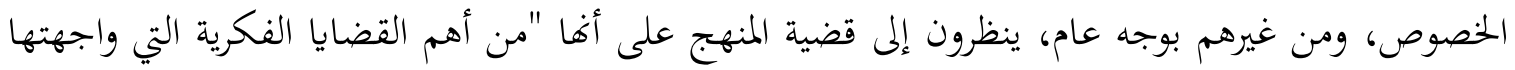
الحركة الإسلامية المعاصرة لأن علاقة المنهج بالحركة علاقة طبيعية وشيجة، فالذي يريد أن يتحرك حركة عاقلة رشيدة لا بد له أن يحدد الغاية التي يريد التحرك نحوها، والطريق الذي يسلكه لبلوغ تلك الغاية. ولأهما كذلك- من أكثر القضايا التي ينبني عليها العمل..، ولأن الخطأ في فهمها يؤدي إلى تطويل الطريق أو اعتسافه، ويؤدي من ثم إلى دفع أثمان باهظة وفقد ضحايا غالية، وقد يؤدي إلى الخمود والركود واليأس والقنوط، وقد يؤدي إلى الفشل إلى غير ذلك من النتائج الخطيرة على سير الحركة.." "35

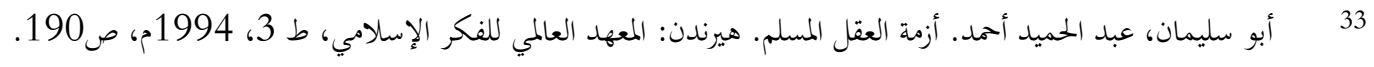

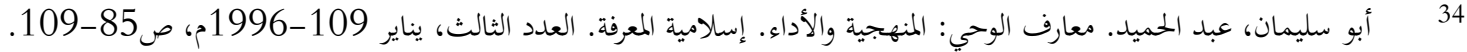

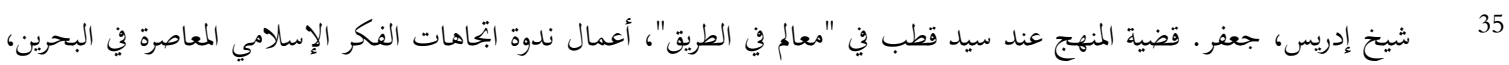

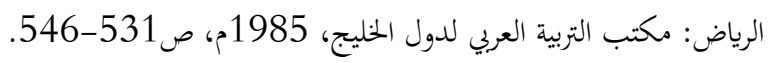


وفي رؤيته للأبعاد الغائبة عن فكر الحركات الإسلامية المعاصرة وممارساتا، يجعل العلواني البعد المنهجي هو "الغائب الأول" أو "الغائب الأكبر"، 36 وهذا يستدعي في نظره تطوير الفهم المنهجي الكلي الذي يجمع بين القراءتين: قراءة القرآن في كليته وقراءة الكون في كليته. فبهذه القراءة وبالتأكيد على الصيرورة والتفاعل والمنطق التاريخي للمتغيرات نستطيع أن ندخل إلى عالم الكتاب الكريم بمنهجية واضحة، نتجاوز فيها ما كان من إشكالات دفعت بابن رشد مثلا إلى كتابة "فصل المقال فيما بين الحكمة والشريعة من اتصال"، أو دفعت بالغزالي لتأليف "تافت الفلاسفة" وردّ ابن رشد عليه في " تافت التهافت". أو تحريم ابن الصلاح للمنطق أو محاولة الاستغناء عن الحد الأوسط في المنطق وتقديم حد بديل من القرآن من أجل "درء التناقض

$$
\text { بين النقل والعقل" في محاولات ابن تيميه. }
$$

هذه نماذج من الوعي بالمنهج لدى شخصيات مختارة من فئات المنظرين في الفكر والحركة والعلم، لكن الوعي بضرورة وجود المنهج شئ وامتلاك مقوماته وعناصره شئ آخر، والوعي لدى الأفراد شئ والوعي العام الذي يشمل فئة العلماء أو فئة الدعاة، بلْه المجتمع بكامله شئ آخر. كذلك فئه فإنّ الوعي بالمنهج ليس مجرد شعار جديد يضاف إلى الكثير مما ينقص الأمة من أجل تحقيق شهودها الحضاري، وإنما هو تحديد فكري وعملي لمجموعة من المتطلبات المنهجية التي يلزم الاستمرار في تداولها وتناولها بالبحث والدراسة والنقد، حتى يشيع "البحث في المنهج مناخا عاما ينشأ عليه عقل الأمة ويشكل جوهر وعيها بالمنهج والشرعة" وقد اقترح سيف الدين عبد الفتاح أربعة عناصر ضرورية لعملية بناء الوعي المنهجي: الوعي بمصادر التنظير المنهجي الإسلامي، والوعي بالإمكانات المنهاجية الغربية المتاحة ومراجعتها، والوعي بالتطبيق المنهجي والتعامل مع مصادر التنظير الإسلامية، والوعي بصعوبات التطبيق المنهجي وكيفية تجاوزها. 38

والأهم من ذلك أيضا أن ينتقل الوعي بالمنهج عند أولئك الذين يكتبون عنه إلى الممارسة العملية للمنهج في مجالات تخصصهم العلمي أو الفكري أو الدعوي.

36 3 العلواني، طه جابر. أبعاد غائبة عن فكر وممارسات الحركات الإسلامية المعاصرة. القاهرة: المعهد العلمي للفكر الإسلامي، 1997م،

$$
\begin{aligned}
& \text { ص63 و74. } \\
& 37 \\
& 38 \text { (الفبد الفتاح، سيف الدين. حول المنهجية الإسلامية... مرجع سابق، ص5-6. }
\end{aligned}
$$




\section{مظاهر الحلل المنهجي في واقع الأمة}

ثمة عوامل عديدة أدت إلى وصول الأمة إلى واقع التخلف الحضاري الذي تعيشه منذ قرون عدة، لكن هناك عوامل أخرى ما تزال تكرّس هذا الواقع المتخلف رغم الجهود المخلصة التي بذها المصلحون. هذا فضلا عن غياب مذهل لبعض العوامل الأساسية في النهوض الحضاري المنشود.

فالشخصية الإسلامية المعاصرة سواء على مستوى الفرد أو على مستوى الجماعة والأمة، اعترقا

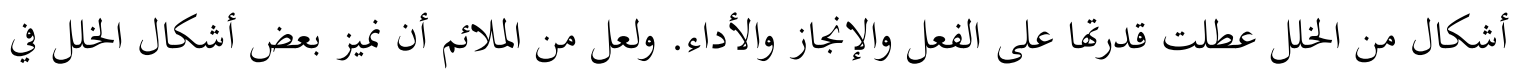
الجانبين الأساسيين من هذه الشخصية: الجانب العقلي أو الفكري، ويتمثل في الرؤية الكونية الكلية التي تحدد تصورات المسلمين عن الكون والحياة والإنسان. فقد اختلطت هذه الرؤية وأصاها الغبش والعجز والقصور في جوانب عديدة. والجانب الآخر هو الجانب النفسي المتمثل في ضعف الإرادة والعجز عن المبادرة و الافتقار إلى الجرأة والشجاعة.

وسيكون من المفيد تركيز النظر على أشكال الخلل في هذين الجانبين ودراستهما دراسة تحليلية عميقة. لكن هناك لونا آخر من الخنلل الذي تعاني منه جهود المسلمين على مستوى الأفراد والجماعة والأمة، وهو خلل يرتبط بجانبي الشخصية الإسلامية المذكورين، ويتمثل في طريقة تفكير المسلمين في مسائل الفهم والشعور والممارسة، فهو خلل منهجي، يتعلق بكيفية تحويل الفكرة إلى واقع أو الانتقال من القناعة الذهنية

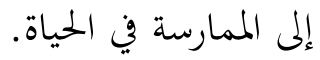

ولاشك في أنّ قيمة الأفكار لا تتحقق في عالم الواقع حتى تتوافر لها طريقة مناسبة تحولها إلى ممارسات عملية في واقع الحياة. وخطورة الخلل المنهجي تتمثل في تعطيل قيمة الأفكار الجيدة عندما يعجز أصحاها عن تقديمها ومعالجتها بمنهج سليم فيخرجوها من عالم التجريد الذهبي والمثل العليا، وربما لا يقتصر الخلل على هذا العجز فقط بل قد تصاغ الأفكار صياغة مغلوطة تشوهها وتصد الناس عن حسن استقبالها وفهمها. وثمة مظاهر لهذا الخنلل المنهجي يمكن أن نميز منها:39

$$
39 \text { 3 النجار، عبد الجميد. عوامل الشهود الحضاري. الجزء الثاني. بيروت: دار الغرب الإسلامي 1999، ص: 39-71. }
$$


ويتعلق ذلك بالطريقة التي يُنظر فيها إلى الواقع الطبيعي والواقع الإنساني وفهمهما. وقد يكون ذلك بإهمال اعتبار الواقع والاعتماد على التصور الذهني المجرد عن الواقع سواء تجريدا عقليا على طريقة الفلسفة اليونانية وما اشتق منها، أو بتريدا روحيا على الطريقة الغنوصية وما تقود إليه. والقرآن الكريم نقل العقل الإنساني من هذا التجريد إلى فهم واقعي لواقع الكون وواقع الإنسان، فآيات الآفاق وآيات الأنفس هي صور الواقع ومعطياته التي يراها العقل الإنساني ويأخذها بوصفها مصدرا للمعرفة والفهم والهداية، ويتمثل هذا الإهمال أحيانا في الزهد الديني الذي يهمل واقع الحياة ومتطلبات الاجتماع البشري فيها، أو في الزهد الاجتماعي الذي يهمل قطاعات عريضة من الواقع الاجتماعي بسبب عزلة النخبة المثقفة وترفعها عن هموم العامة، أو زهد في الواقع نتيجة اليأس من إمكانية إصلاحه بتجنب قضاياه أو مواجهة أصحابه بأفكار التكفير وممارسات العنف.

وينتهي الأمر نتيجة لهذه الأشكال والصور من إهمال الواقع إلى الجهل به والعجز عن التعامل معه نتيجة لهذا الجهل. ويلاحظ في هذا المقام كيف أنّ الغربين قد أنجزوا حضارقم لأسباب منها فهم الواقع ودراساته دراسة عميقة وشاملة استوعبت عناصره وأبعاده وتفصيلاته.

وزاد الطين بِّبلّة زهدُ المسلمين ليس في فهم واقعهم فحسب بل في فهم الواقع الإقليمي والدولي

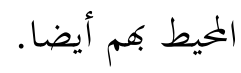

إنّ هذا الخلل المنهجي في التفكير والسلوك في شأن واقع الحياة الإسلامية والإنسانية امتد لمحاولة نقض الواقعية في الفكر والواقعية في التعامل، وهو ابتحه نفسي ينتهي عادة إلى الرفض المطلق دون اعتبار التفاصيل والمعطيات.

ومن صور الجهل بالواقع عند فئات من المسلمين التشبث بالمثال، فهؤلاء يتخيلون صورة مثالية وهمية في التاريخ الإسلامي يستأنسون بالهروب إليها من واقعهم. ويقصرون فهمهم لمنهجية الإصلاح على محاولة 
استنساخ الصور الجزئية من المثال وإجرائها على الواقع أو على منهجية الاستدعاء الآلي للمثال السلفي في كل معالجة للواقع.

ومن هذه الصور الجهل بأثر الواقع العالمي في تكييف فهم المسلمين لبعض مبادئ الدين، أو اكتشافهم لهذه المبادئ وكيفيه تفعيلها في الواقع المعاصر، بعد أن كان المألوف هو النظر إليها بوصفها نصوصا نظرية أو أحداثا تاريخية مؤطرة في سياق الزمان والمكان وما رافقهما من مثاليات. فكثير من جوانب فهم هذه المبادئ اليوم هو انعكاس لما يراه المسلمون في واقع غيرهم. فالحرية والمساواة والعدالة والشوري، أصبح لها في الواقع المعاصر مؤسسات وتشريعات يتمنّى كثير من المسلمين لو يروها في حياتم في بلداغم، ومع ذلك يظهر الخلل المنهجي في إنكار تأثير ممارسات هذه المبادئ في عالم غير المسلمين على فهم المسلمين لهذه المبادئ.

وهذا الحلل المنهجي يقع فيه حتى بعض العلماء المعاصرين من ذوي الشأن والمكانة في نفوس المثقفين والعامة من المسلمين.

ولعلّ إهمال واقع المسلمين كان يعززه لدى بعض الفئات خلل منهجي آخر يعتمد الواقع الغربي مثالا للنهوض والتقدم. والخلل هنا هو في صياغة برامج للإصلاح مشتقة من تلك المثالية الغربية ومنزلة على واقع

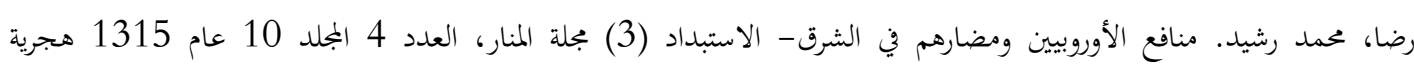
40

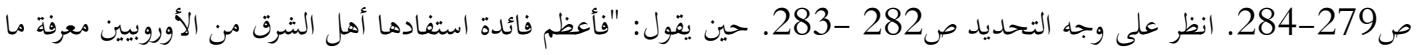

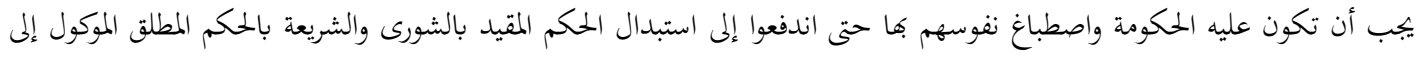

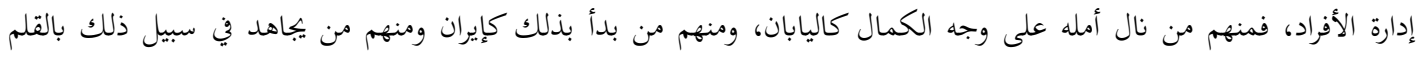

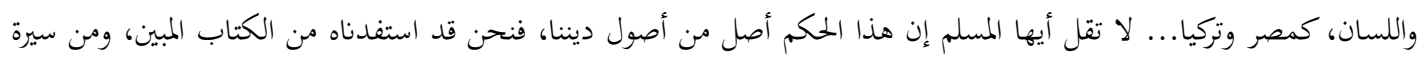

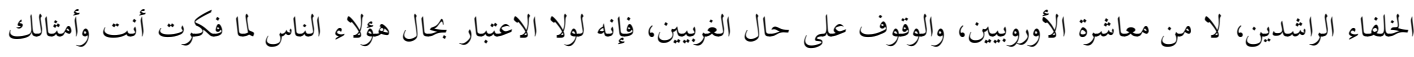

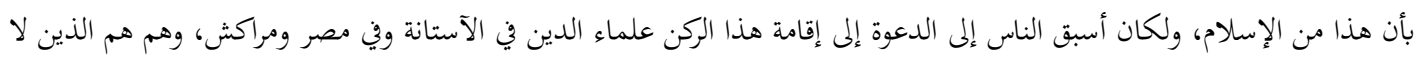

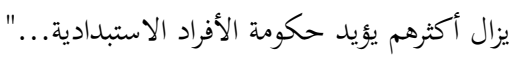

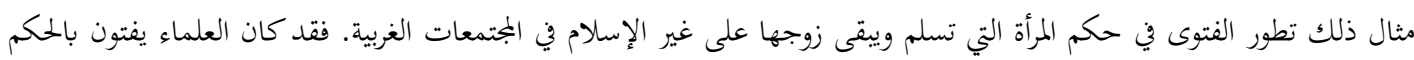
41

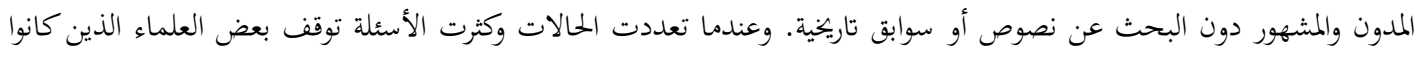

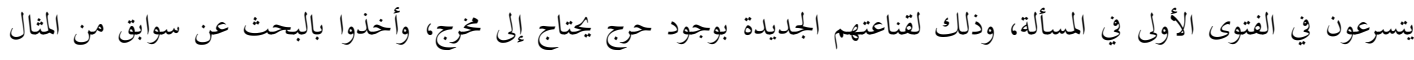

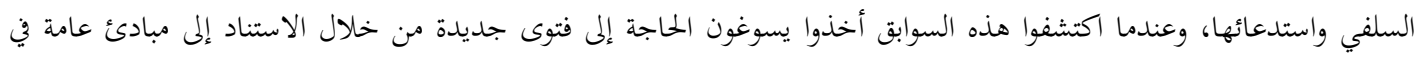

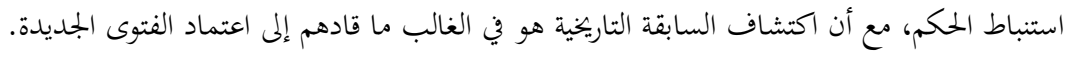


المسلمين بصرف النظر عن عناصر هذا الواقع والخصوصيات الثقافية والاجتماعية له. وخطورة هذا المنهج في النظر إلى سبل الإصلاح أنّ أصحابه هم أهل النفوذ والمراكز المهمة في صنع القرار رغم محدودية القاعدة الشعبية عندهم وعزلتهم عن الجماهير. لكن هذه المثالية في النظر أشد انخرافا منهجيا وأعمق خللا.

وقد يحسن في هذا المقام أن نشير إلى أن الجهد الإصلاحي في الفكر الإسلامي الذي قام به شيخ الإسلام ابن تيمية كان مبنيّا على فهم الواقع ومستجداته ومنهج المرونة في التعامل مع أحداثه وقضاياه، دون أيّ مساومة على أصول السلف، مما عدّ بحديدا أصيلا في حيوية الفكر الإسلامي. ومن المؤسف أن هذا المنهج التيمي الواقعي النقديّ لم يجد من بعده من يعمّق مجراه ويوسّع مساراته، فانكفأت الأمة في غيبوبة من الجهل بالواقع وضمور الوعي بمتطلباته. 42

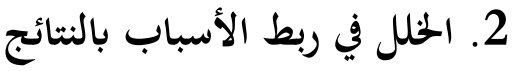

وفي ذلك بتاوز للقانون السببي ومفهوم السببية ووقوع في التفسيرات الخرافية والأسطورية. ويعدّ مفهوم السبية في الإسلام قانونا طبيعيا واجتماعيا ونفسيا في نطاق التدبير الإلمي للكون وتصريفه لشؤونه، فما يجكم علاقة الإنسان بالطبيعة هي أسبابٌ بها يكون التمكين له فيها أو لا يكون، وهذه الأسباب هي قوانين ماضية لا تتخلّف إلا إذا أراد الله خرقها في حالات معينة ولغايات محدودة، لا تقع ضمن الحسبان البشري ولا المسؤولية البشرية.

ويتمثل الخلل المنهجي في فهم الأسباب والتعامل معها بعدم الأخذ بالأسباب بحجة التوكل على الله أو الظن بأنّ اعتماد الأسباب يطعن في العقيدة لأنّ الله سبحانه هو الفاعل الوحيد أو بالتخفف من تحمل مسؤولية النتائج والوقوف عند حد الأخذ بالأسباب لأنّ النتائج في ظنهم من فعل الله سبحانه لا من أسباهما ومقدماتا، أو بإهدار البُعد الغبيب جملة في فهم الأسباب والظن بأنّ الأسباب هي الفاعلة بذاتما في النتائج دون أن يكون للقيوميّة الإلهية دخل في ذلك. 
وهذا الحلل هو عرض" عام يعبر عن ضعف الحس السبي بتحاه مظاهر الطبيعة وظواهر الاجتماع وضعف عقلية البحث العلمي المتمثلة في الخطوات المنطقية في التحليل والترتيب والتصنيف اللازم لعناصر أية مشكلة أو ظاهرة بحيث يسهل الكشف عن حقيقة العلاقات السببية بين هذه العناصر ويكون ذلك أساسا للفهم ومن ثم أساسا للحل والعلاج.

\section{3. الحلل في النظرة الكلية والثمولية:}

يقتضي المنهج السليم في التعامل مع أي قضية أن ينظر إليها ويتعامل معها ضمن الدائرة التي تقع فيها أو تنتمي إليها، واعتبارها عنصرا في مجموعة أشمل، بينها وبين العناصر الأخرى من سمات الشبه والتمايز ما يُمكن الباحث من رؤية الأجزاء ضمن الكل، والكشف عن خصائص القضية من زوايا نظر مختلفة، ويبني التعامل معها مع تقدير صحيح للآثار المترتبة على هذا التعامل.

وخاصية الشمول في منهج التعامل الإسلامي مع أي قضية بتمع عالم الشهادة مع عالم الغيب وجوانب النفع والضرر وواقع الحال واعتبار المآل، والواقع المحلي وما يهيط به من أبعاد، والآثار العاجلة

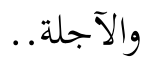

ويتحقق الخلل المنهجي في هذا السياق عندما يقصر الأمر على جانب من القضية وعلى قليل من معطياتما وعلى الظاهر من أمرها. ويتمثل هذا الخلل أحيانا في البحث عن الحقيقة في حيز ضيق ومحدود من مجالات المعرفة بالاقتصار على التراث دون المستجدات، بل إنّ المنهجية الجزئية في النظر إلى التراث اقتصرت على الجانب الفقهي منه دون أن تستوعب مصادر التأسيس في الكتاب والسنة، أو على الجانب النصّيّ منه وما يتفرع عنه دون أن تستوعب بجالات التطبيق والهداية التي يتقصدها النصّ في مسائل الكون والمادة والعمران، وقد تقتصر على مذهب من مذاهب الرأي والفقه دون المذاهب الأخرى التي تعمّق الفهم وتغنيه وتعبّر بصورة أوسع عن فهم الدين ومقاصده.

ويتمثل هذا الخلل أحيانا في النظرة الجزئية للزمن واقتصار التقدير فيه على حيز محدود من الزمن. ومقاصد الدين لا تتحقق في أي حكم من الأحكام إلا إذا أخذ الحكم بعين الاعتبار الماضي للاعتبار به، 
والحاضر لعلاج قضاياه، والمستقبل بما يتوقع فيه من آثار الحكم ومضاعفاته. ولعلّ أكثر ما يلفت الانتباه في هذا المجال هو ضعف الحسّ بالمستقبل وتقدير متطلباته في التخطيط؛ وليس الاجتهاد -في حقيقة الأمر - إلا وصْلا للزمن ببعضه؛ إذ هو استهداء بالوحي المطلق عن الزمن لاستنباط حلول لمستجدات الحاضر بالاستنارة باجتهادات السابقين في الماضي (لحاضرهم) وبحساب آثار حلول الحاضر على المستقبل ومستجداته.

ومن ذلك الخلل أيضا تجزئةُ النظر والبحث في القضايا والمشاكل لتقدير الأحكام فيها، وذلك خلل منهجي في التناول الفكري لتحليل القضايا والمشكلات لتقدير أحكامها وحجم أولوياتا في ضوء معطيات الواقع وإمكاناته. فإعلاء منزلة بعض الجزئيات من الأخلاق والتصرفات والشعائر وشدة التمسك بها على أها مادة للدعوة ومقياسا للعمل في معزل عن كليات الدين ومقتضيات الدعوة والواقع يلحق الضرر بالكليات وبالدعوة ذاها.

وحين يشتد تمسك بعض الأفراد أو الفصائل بما تقدر أنه أكثر أهمية ينتهي الأمر إلى الشقاق والاختلاف، مع أن الأمر لا يعدو أن يكون اختلافا في تقدير بعض المسائل الفرعية أو الاجتهاد في بعض وسائل العمل، تضيع معه مصالح أكثر أهمية من وحدة المسلمين وتضافر جهودهم لإعلاء شأن الدين

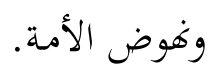

فهذه الاختلالات النابحة عن فقدان الرؤية الكلية الشمولية تفضي إلى فقدان الرؤية الصحيحة التي تقدر الأشياء بحسب أحجامها الحقيقية وترتبها بحسب أهميتها؛ فما هو جزئي صغير يقدر على أنه كلّيّ كبير، وعندما لا يكون التقدير على أساس من المقارنة التي هي من خصائص الشمول، ينتهي الأمر إلى

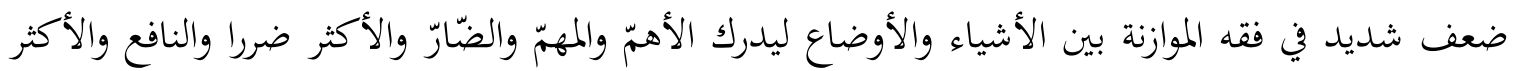
نفعا.. كما ينتهي الأمر إلى ضعف شديد في فقه الأولويات الذي به ترتب الأمور بحسب أولوياتا في الأهمية

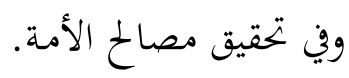

إنّ الخلل المنهجي المتمثل في فهم مبادئ الواقعية والسببية والشمولية في واقع المسلمين الفكري والعملي يُعدّ عائقا مهما في سبيل الإقلاع الحضاري الإسلامي المنشود. 


\section{أهمية البحث في المنهجية الإسلامية والتفكير المنهجي}

تتعلق المنهجية بعملية التفكير الإسلامي وطبيعة الفكر الذي ينتج عنها. وترتبط بغايات الإسلام ومقاصده العامة. ولذلك فإن قضية المنهجية في بعدها الفكري لا تنفصل عن الواقع والحياة التي يستهدف الإسلام بناءها في المجتمع المسلم. فغاية الفكر الإسلامي إقامة الحياة الإسلامية في الدنيا لتكون الممّر إلى الدار الآخرة. وإذا غاير الفكر الإسلامي الحياة الإسلامية أو انعزل عنها فإنه يفقد فاعليته وتتجاوزه الحياة. وكذلك الحياة الإسلامية إذا غايرت الفكر الإسلامي ضلّت الطريق إلى إسلاميتها وسقطت في متاهات القيم والتصورات الأخرى. لكن انتفاء المغايرة لا ينفي التميّز والاختصاص. فالمنهجية الإسلامية العامة تنبثق عنها مناهج عديدة متخصصة متمايزة بتمايز العلوم والمجالات المعرفية.

ولا شك في أن قضية المنهجية هي إحدى قضايا فلسفة العلوم في التصنيفات المعاصرة لمجالات المعرفة العلمية وتخصصاتما. وتكشف أية محاولة لرصد واستعراض الأدبيات المعاصرة التي تهتم بالرؤية الإسلامية لمجالات فلسفة العلوم عن غياب كبير، فيما عدا جهود فردية متناثرة تتعلق بتاريخ التراث العلمي للمسلمين. " أما باقي موضوعات فلسفة العلوم التي تعالج وتحلل لغة العلم وتاريخه ومنهجه ونظريته وكل ما يتعلق بمسيرته، فيمكن القول إذا ما زالت بكرا في انتظار من يتناولها بالدراسة الأكاديمية المتأنية من منظور إسلامي".

ثمّة وجوه عديدة تتؤكد الحاجة إلى دراسة المنهجية الإسلامية، فالغزو الثقافي الغربي الحديث للعالم الإسلامي اليوم يؤسس رؤيته على منهجية خاصة لابد من بيان مقولاتما وكيف تفهم في ضوء مقولات المنهجية الإسلامية، وأية مناقشة أو مقارنة لهاتين المنهجيتين لابد أن تكون مناقشة للمبادئ والأسس النظرية كل منهما.

وحين ينظر "مشروع إسلامية المعرفة" إلى قضية "لمنهجية الإسلامية" بوصفها مورا أساسيا في "الأزمة الفكرية" التي تعاني الأمة منها، وحين يؤكد المشروع على تضافر الجهود اللازمة لبنائها وبلورتا بوصفها قاعدة

$$
43
$$

44 
أساسية في المشروع الحضاري الإسلامي الذي تحاول الأمة بناءه، حين يتم ذلك ينصرف الذهن إلى أدبيات المنهجية وبحوثها وإلى المظانّ التي يتوقع أن يجد فيها هذه الأدبيات، وعند التحقيق نجد ضعفا كبيرا في التأليف والكتابة في مجال المنهج باعتباره حقلا معرفيا، ونجد أن ميادين التأسيس المنهجي والرؤية النظرية في المنهج غير مطروقة تماما في الدائرة الإسلامية، وأن القليل المتوافر من الأدبيات حول الموضوع محدود في التنبيه

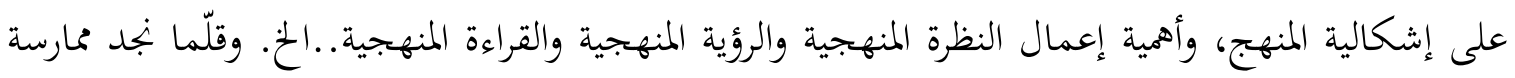
منهجية في المجالات المعرفية المختلفة يقوم بها أهل الاختصاص في هذه المجالات.

قضية المنهجية عند إسماعيل الفاروقي قضية مركزية في مشروع إسلامية المعرفة. وينطلق إسماعيل الفاروقي 45 في توضيحه لمسألة المنهجية من تحديد طبيعة الجها اللازم لإعادة بناء الأمة المسلمة ولتمكينها من أداء الأمانة، على اعتبار أن الأمة تعاني من انخراف خطير يتهددها، ويلزم تطوير علاج لأزمتها، ولتمكينها من ثمّ من تحمل مسؤولية قيادة العالم. ولا يرى الفاروقي أدنى شك في أن منبع داء الأمة ومحوره هو النظام التعليمي السائد الذي حرص الاستعمار والحكومات الوطنية بعد الاستقلال على تكريسه. هذا النظام يقوم على ازداوجية بين تعليم عام علماني يعدّ نسخة مشوهة عمّا عند الغربيين، يفتقد فيه المتعلمون منهج التفكير الإسلامي، وتغيب الرؤية الإسلامية عن محتوياته، وهو النظام المسؤول عن تخريج قيادات المجتمع؛ وتعليم إسلامي تقليدي يفتقد الاحتكاك بالواقع، ودورُ خريييه دورٌ محدود لا يمكن أن ينافس دور خريجي

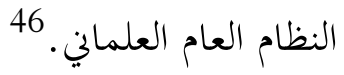

إنّ علاج أزمة الأمة في نظر الفاروقي يبدأ من ضرورة توحيد نظامي التعليم في نظام واحد يغرس الرؤية الإسلامية ويكشف عن طبيعة الحضارة الإسلامية وخصائصها، ويعيد صياغة كل المعارف الحديثة في

45 4 الت هذه القضية موقعاً معورياً في الورقة التي قدمها رمه الله الفاروقي للمؤتمر العلمي الثاني لإسلامية المعرفة في باكستان عام 1982 م.

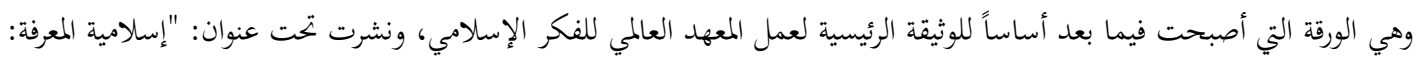
المبادئ العامة وخطة العمل".

46 Al-Faruqi, Ismail. Islamization of Knowledge: Problems, Principles and Prospectives. In: Islam: Source and Purpose of Knowledge. (Proceedings of Selected Papers of the Second Conference on Islamization of Knowledge, Pakistan,1982.) Herndon, VA: IIIT, 1988, pp. 15-63. 
مناهج التدريس من منظور إسلامي، ويمكّن الأمة من بناء معرفة إسلامية معاصرة، تجمع الوحي والعقل، وتوحِّدُ الفكر والفعل، وتقود إلى عمران الدنيا ونعيم الآخرة. فهو نظام تعليمي توحيدي بكل ما في الكلمة من معنى. ومن هنا فإن المنهجية المطلوبة لهذا الغرض لا يمكن أن تستمد من المنهجية الغربية السائدة، وكذلك فإن المنهجية الإسلامية التقليدية الموروثة عاجزة عن تحقيق ذلك.

ويتوسع الفاروقي في بيان عجز المنهجية الإسلامية الموروثة، فيلاحظ أن الأمة الإسلامية افتقدت منهجيتها التوحيدية التي بنت المجتمع المسلم والحضارة الإسلامية على أساسها، وقد افتقدت الأمة هذه المنهجية بعد أن أصاهما ما أصاها من الكوارث والتدمير، إلى الحدد الذي فقدت فيه القيادات العلمية ثقتها بقدرةا على صيانة الشخصية الإسلامية، واكتفت بالتمسك بظاهر نصوص الشريعة دون فهم المقاصد، وإغلاق باب الاجتهاد، واعتبار كل خروج على تراث السلف بدعة مذمومة.

تم ذلك في الوقت الذي كان فيه الغرب في مرحلة الصعود في مجالات القوة والتصنيع والاكتشاف والتوسع الاستعماري، فسيطر على معظم أطراف العالم الإسلامي حتى واجه دولة الخلافة وقضى عليها، وقسم ما بقي من بلدان المسلمين. وتحت ضغط الجهل والتخلف والضغط الاستعماري حاول زعماء المواقع الكبرى في العالم الإسلامي يومذاك في تركيا ومصر والهند إقامة هضة على أسس غربية على أمل أن تدبّ في الأمة روح الحياة، فلم ينجح التغريب إلا في سلخ طوائف من الأمة عن إسلامها في بعض البلدان، وتمزق بلدان أخرى بين النظام الغربي العلماني والنظام الإسلامي التقليدي. 47 وهكذا بتحد الأمة نفسها اليوم في نظر الفاروقي بين منهجيتين: منهجية غربية علمانية غير قادرة على إحياء الأمة وإصلاحها، ومنهجية إسلامية تقليدية لا تقل عجزا هي الأخرى عن إصلاح واقع الأمة. وقد لخص الفاروقي أسباب عجز المنهجية التقليدية في وجهين: الأول، أها تحصر مفهوم الاجتهاد في بجال الفقه وتحصر معنى الفقه في الأحكام والتشريعات القانونية التي عرفتها المذاهب الإسلامية، وقد تم تحاوز المعنى القرآي الواسع لمصطلح الفقه الذي فهمه فقهاء الإسلام العظام، ذلك الفهم الذي يشمل الإدراك والوصول إلى العلم والمعرفة وتحديد المبادئ الأساسية للفهم الأساسي للحياة والواقع، وبذلك انحصر فقهاء اليوم في 
الإفتاء بالحل والحرمة إلى الحد الذي أصبحوا عاجزين فيه عن الاضطلاع بالمسؤوليات التي غض بها العلماء

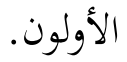

أما الوجه الثاني لعجز المنهجية التقليدية فهو حب الاغتراب في الدنيا وإهمال شأها وتركها للطغاة والمستبدين والفاسدين والتحليق في المثاليات الصوفية. صحيح أن التصوف بقي المصدر الوحيد المفتوح في فترة الجمود على التراث، وأسهم بما يوفره من تزكية نفسية وروحية في حماية الهوية والإشباع الروحي والتأثير بالقدوة الحسنة لجذب الكثير من الشعوب إلى الإسلام، فضلا عن أثره في بعض الفترات في إثاره حوافز الجهاد ومواجهة الأعداء، لكن هذا المصدر بتمد أيضا وأصبح يدعو إلى منهجية انعزالية تقوم على أساس حدسي خالص وتجربة ذاتية كرست الغربة بين العقل والوحي.

وينتهي الأمر بالفاروقي بالدعوة إلى منهجية جديدة لا قدرة للفقهاء التقليديين حتى على تصورها؛ منهجية يتم استمدادها من فهم جديد لطبيعة الأصول في الإسلام، ليس بوصفها أصولا تقليدية للفقه بمعناه التقليدي، وإنما بوصفها مصادر المعرفة الإسلامية. 48

من هنا كانت دعوة الفاروقي إلى أسلمة المعرفة بوصفها أساسا ضروريا لإزالة الثنائية في النظام التعليمي، وإزالة الثنائية في حياة الأمة، وتحاوز أسباب العجز في المنهجية التقليدية. وقد حدد الفاروقي ملامح عديدة لهذه المنهجية، ولكنها تدور في بجملها على مبادئ التوحيد في التصور الإسلامي، فهي منهجية توحيدية تقوم على أساس وحدة الخالق، ووحدة الخلق، ووحدة المعرفة، ووحدة الحياة، ووحدة الإنسانية.

وفي مواجهة الذين يقولون إن لفظ الإسلامية لا يلحق بالمنهجية، باعتبار أن المنهجية أداة موضوعية مستقلة عن ثقافة الباحث وموضوعات بكثه، يعتقد عبد الحميد أبو سليمان50 بوجود منهجية إسلامية

$48 \quad$ Ibid., p.35.

49 Ibid., p.38-52.

عبد الحميد أبو سليمان واحد من القلاثل الذين كان لهم إسهام كبير في لفت الانتباه إلى القضية المنهجية في الفكر الإسلامي وأهمية التفكير المنهجي، وذلك من خلال المؤسسات التي أسهم في إنشائها وإدراة نشاطاتما وبرابجها لخدمة قضية المنهجية ومن خلال ماكتب 
متميزة عن منهجيات الأمم والحضارات الأخرى. ولكنه يرى أن هذه المنهجية ليست نصّا منزلا يقف

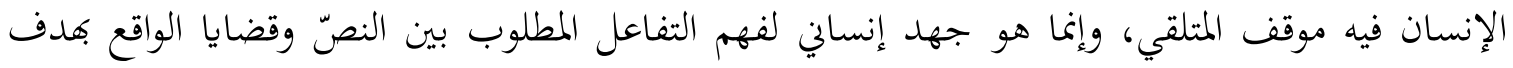
تحقيق غايات الدين ومقاصده. وأن هذه المنهجية في حالة نمو وتطور لتستجيب باستمرار لمستجدات الواقع

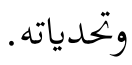

فمفهوم المنهج ومسارات تطوره ونجاحاته الأولى وإخفاقاته التالية أمور تحتاج إلى دراسة ونظر؛ وسيجد أبو سليمان مثلا أنّ المنهج الإسلامي الذي تم تطويره وتطبيقه في المراحل المبكرة من حياة الأمة المسلمة وتمثل في تكامل مصادر المعرفة -الوحي والكون- وتحرير العقل الإنساني وإطلاق طاقاته، كان أساسا كافيا لبناء دعائم الحضارة الإسلامية وأعطى أمم العالم دفعة حضارية في جميع المجالات، إلا أن ذلك المنهج التقليدي وقف قاصرا عن حلّ عدد من الإشكالات المتعلقة بفهم النص، كما هو الحال في مسألة النسخ في القرآن أو المتعلقة ببعض المعاملات المالية والاقتصادية كمسألة الربا. والسبب في توقف فاعلية ذلك المنهج في رأي "أبو سليمان" هو المشكلات المبكرة التي طرأت على واقع الحياة السياسية والاجتماعية في المجتمع الإسلامي حيث استبد السلطان بالإدارة العامة والسياسة، وتراجع العلماء أو أجبروا على التراجع عن المواقف والقضايا العامة للأمة ليشتغلوا بالفقه وقضايا الفكر المعزول على الفعل في الواقع. فكانت نتيجة ذلك الاقتصار على المتابعة والتقليد وتوقف إبداع العقل.

وقد خصص لؤي صافي كتابا إضافيا5 لبيان مدى الحاجة إلى منهجية إسلامية معاصرة لتطوير الثقافة الإسلامية والمعرفة الإسلامية المعاصرة. وقد بين في الفصل الأول من كتابه ثلاثة عناصر أساسية تبيّن

ونشر حولا، حتى إن المتابع لما يكتبه أبو سليمان أو يتحدث به ليجد لفظ المنهج والمنهجية يكاد يتكرر في كل فقرة من حديثه. أنظر

مثلا:

أبو سليمان، عبد الحميد أزمة العقل المسلم. هيرندن: المعهد العالمي للفكر الإسلامي 1993 (الفصل الثالث بعنوان منهجية الفكر

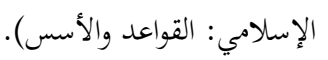

AbuSulayman, A. Towards an Islamic Theory of International Relations: New Directions for Methodology and Thought. Herndon: IIIT, 2nd Ed., 1993, PP 64-96.

51 Safi, Louay. The Foundation of Knowledge: A Comparative Study in Islamic and Western Methods of Inquiry. Kuala Lupmur, Malaysia: International Islamic University and the International Institute of Islamic Thought. 1996. 
وجه الحاجة إلى هذه المنهجية ثم الصعوبات التي تكتنف تطويرها، ثم مسائلها. ويحدد صافي مفهوم المنهجية الإسلامية المطلوبة بمدى توافر الطرق العلمية التي يستخدمها الباحثون بصورة تنسجم مع المعايير والاهتمامات الإسلامية، ومور الاهتمام الذي يبرر عنده البحث عن هذه المنهجية هو مدى حيادية البحث العلمي؛ مفترضا أن شروط استعمال طرق البحث حتى الفنية البحتة منها لا يمكن أن توصف بأها فنيّة بحتة، وأن المنهجية الغربية السائدة منذ فرانسيس بيكون ورينيه ديكارت حتى اليوم تحمل بالضرورة خصوصيات غربية تنبع من التحيّز الوضعي والمذهب السلوكي، وحتى عندما أصبح كثير من العلماء الاجتماعيين الغربين يستبعدون المذهبية السلوكية، فإننا لا نجد لديهم تغييرا جوهريا في أنماط البحث، بقدر ما هي حركات استراتيجية تستهدف إسكات الناقدين.52

يمارس صافي في فصول كتابه نظرة تحليلية ناقدة للمنهجية الإسلامية التقليدية التي استخدمها العلماء المسلمون في السابق والقائمة على أصول الفقه والمنهج القياسي، ويمارس نفس النظرة للمنهجية الغربية المعاصرة المستخدمة في العلوم الاجتماعية والمستمدة أساسا من مناهج العلوم الطبيعية، ويقترح في الفصل الأخير منهجية توحيدية تعتمد التكامل بين اعتبار الوحي مصدرا أساسيا للمعرفة، والطموح إلى تطوير أدوات وإجراءات لتحليل النصوص والأحداث والظواهر، وهذه الأجراءات يمكن اشتقاقها من كل من الخبرة التاريخية للمنهجية الإسلامية التقليدية والمنهجية الغربية المعاصرة، دون أن يقدم الباحث مزيدا من التوضيح لمذه الإجراءات أو أمثلة عليها.

وقد تسلل كثير من الباحثين المعاصرين في التراث الإسلامي إلى تشويه هذا التراث وتقطيع أوصاله بالتسلل من ثغرة المنهجية، حين استعار هؤلاء مناهج غريبة عن التفكير الإسلامي وأعملوا أطرا مرجعية غريبة عن الثوابت الإسلامية، فلا أرضا قطعوا في نقد التراث وتحليله وقراءته في سياقه التاريخي وسقفه المعريف، لتنقيته من العناصر الميتة التي يلزم بتحاوزها، ولا ظهرا أبقوا من التراث لاستخراج العناصر الحية منه وتوظيفها في إصلاح الواقع الإسلامي المعاصر. في هذا المجال نرى طه عبد الرمن ينعى على كثير من الباحثين الذي يشتغلون بالتراث الإسلامي دراسة وتقويما مستخدمين منهجية منقولة من سياق ثقافي آخر، ويرى أن الأولى

$52 \quad$ Ibid., p. 5.

53 Ibid., p. 192. 
أن نقتس المنهجية التي أنتجتها الممارسة الثقافية نفسها، والتي يمكن استعادتا نتيجة اتبّاع مجموعة من المبادئ النظرية والعملية، من أهمّها تحصيل معرفة شاملة بمناهج المتقدمين من علماء الإسلام ومفكريهم في مختلف العلوم، مع تحصيل معرفة كافية بالمناهج الحديثة التي تمكن الباحث من بحاوز طور التقليد واقتباس النظريات إلى طور الاجتهاد في اصطناع المناهج ووضع النظريات. 54

يتحدث محمد حسين فضل الله* عن البعد المنهجي في حاجة الأمة إلى التجديد، فيؤكد أن العلماء

الأقدمين قد فكروا بالطريقة التي: "تحكم مناهج التفكير عندهم من الواقع الذي عاشوه وتأثروا به ومن الثقافات المهيمنة على عصرهم، وقد قاموا بدورهم الثقافي خير قيام. ولكن ليس معنى ذلك أن منهجهم كان يمثل منهج الحقيقة المطلق الذي لا يمكن أن يتجاوزه الزمان، بل كان يمثل تجربة إنسانية محدودة الملامح والأبعاد والامتدادات، فيمكن لنا أن ندخل في بحربة جديدة قد تغيّر الكثير من المفاهيم وتطور الكثير من النتائج." وفي مواجهة العبارة المشهورة في التراث الإسلامي التي تقال في سياق مدح السابقين ونصها: "ما ترك السابق للاحق شيئا"، يعقب الشيخ فضل الله قائلا: "وكم ترك الأول للآخر !"

ويخاطب الشيخ فضل الله مشاعر الذين يتحسّبون أن التجديد يمكن أن يكون قطيعة مع التراث فيؤكد أن التجديد هو محاولة جديدة لفهم التراث وتطويره في التجربة الاجتهادية على أساس القواعد الأصيلة في المنهج، وأنه لا يجوز بتحاوز المضمون الأصيل في المصادر الإسلامية الرئيسة، لأنّ هذا المضمون يمثل القاعدة الإسلامية، فالمعاصرون والأقدمون سواءٌ في ضرورة التوفر عليه والانطلاق منه في نتاج الفكر والفقه والمنهج. ويقرر: "إن الفكرة التجديدية لا تنطلق من انقلاب على الماضي.. بل تنطلق من إعادة النظر فيه من أجل فهمه بطريقة منهجية جديدة لاختلاف قواعد فهم النص بين المنهج القديم والمنهج الجديد." ويقترح لتيسير الاجتهاد والتجديد طرقا وآليات تتضمن الجها الجماعي الذي تقوم به مجموعات من المفكرين من علماء الكلام والأصول والفقه والفلسفة وغيرهم من الذين يساهمون في الثقافة المعاصرة، لدراسة المناهج من حيث الشكل والمضمون من أجل القيام بحركة بتديدية بطريقة علمية حديثة. ويرى أن تنوع المجتهدين

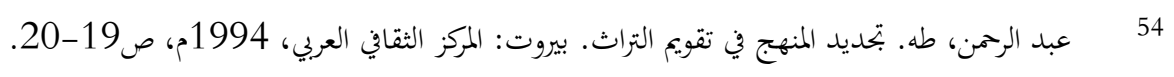

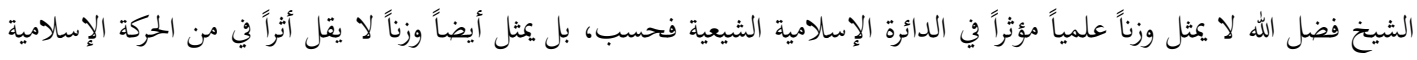


والمفكرين يؤدي إلى التكامل في الأفكار والمناهج والأساليب بحيث تنطلق الحركة التجديدية للكتاب وللمعالجة ولمنهج من مواقع متعددة بتمع الجهات المختلفة لتبرجها في برنامج واحد. ويلفت الانتباه إلى كالى ضرورة عقد المؤتمرات العلمية التي تتيح حرية الفكر والنقاش في كل شئ: "فالملحوظ أن الواقع الذي يعيشه الفكر الإسلامي لا يزال خاضعا للفرد في حركثه، كما لا يزال محكوما للجوّ السائد الذي قد يفرض مفاهيمه وتصوراته بالقوة مما يؤدي بالمفكرين الطليعيين إلى الانكماش ومواجهة الموقف بطريقة التقية، لأفم يخافون من ضغط الغوغاء العلمية -إن صح التعبير - كما يخافون من الغوغاء الشعبية." أما الميادين التي يلزم فيها التجديد فيشير إلى علوم الكلام والفقه والأصول، لأن مفرداتها الفكرية هي نتاج مرحلة سابقة، وكذلك الأمر في خطاب الحركات الإسلامية التي استهلك الزمن الكثير من مفرداته. 55 يبين طه عبد الرحمن أن الأمة تعاني من "نقص منهجي خطير" حيث لا يتوافر لكثير ممن يتصدون لتجديد النظر في مناهج الإسلام من القدرات بالقدر الذي كان يتحلى به المتكلمون في التاريخ الإسلامي من ضبط المناهج العقلية والأخذ بالقويم من الأدلة المنطقية. وهو يرى بطبيعة الحال أنهّ لا بجال لإنكار فضل المتكلمين في مواجهة التيارات الاعتقادية غير الإسلامية والاتحاهات الفلسفية القائمة على العقلانية والدهرية، من حيث إنّ علم الكلام قد جمع إلى موضوعه الذي هو أصول العقائد الإسلامية مناهج نظرية وتناظرية.. وعليه فإنه يدعو إلى استعادة الأمة لطاقتها الإبداعية في الإنتاج الفكري الكلامي لمواجهة النزعات المادية والتاريخية التي تطغى على العالم المعاصر... ومن ثّّ لا بد من استكمال العدّة المنهجية اللازمة.

ولكن أحمد الريسوني يرى أن ارتباط الفكر المنهجي الإسلامي بعلم الكلام لم يكن خيرا كله؛ فإن إحدى المشكلات التي وقع فيها الفكر الإسلامي القديم هي ارتباطه إلى حد كبير بعلم الكلام وما تولّد عنه

خضل الله، حمد حسين. الأصالة والتجديد، المنهاج (بجلة فصلية تصدر عن مركز الغدير في لبنان)، 1 (2)، صيف 1996، ص59-

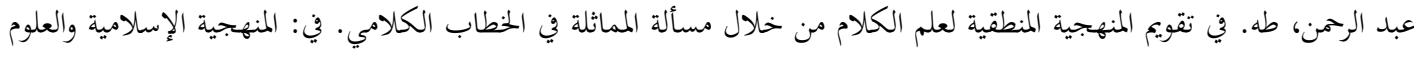
56

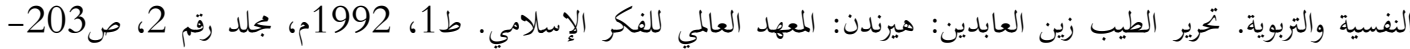


من تشعبات و تأثيرات، وغفل في المقابل عن المقاصد مضمونا ومنهجا، ولا بد للفكر الإسلامي الحديث حالا واستقبالا أن يستفيد من المقاصد والمنهج المقاصدي. 57

ويذكر الريسوني جملة من مبررات الاهتمام بالمقاصد، منها أن التفكير المقاصدي هو تفكير منهجي في الأساس؛ "فالمقاصد بأسسها ومراميها وبكلياتا مع جزئياتا و بأقسامها ومراتبها وبمسالكها ووسائلها تشكل منهجا متميزا للفكر والنظر، والتحليل والتقويم، والاستناج والتركيب."58 وإذا استقامت مناهج التفكير على أساس المقاصد فإن الفكر سيكون فكرا قاصدا يمدد مقصوده، ومن ثمّ تتحدد أولويته ومشروعيته، وبالتالي جدوى المضي في أمره. وتتعزز ضرورة الاهتمام هذه المناهج من ملاحظتنا أن كثيرا من المفكرين والمنظرين يفتقدون العقلية الترتيبية التي توضّح أولوية المصالح والمفاسد في الشؤون كافة، كما يفتقدون العقلية التركيبة التي تستقري الجزئيات وتربط بينها لتصل إلى القضايا الكلية. والمنهج المقاصدي يوفر العقلية الترتيبية والعقلية التركيبية معا؛ فالمقاصد تقوم على الاستقراء والتركيب مثلما تقوم على المفاضلة والترتيب، "والاستقراء هو أرقى المناهج، والمعارف الاستقرائية الكلية هي أرقى المعارف وأقواها."59

وفي هذا السياق تأتي ملاحظة حسن جابر 60 حول الحاجة إلى التأسيس المنهجي لكيفية الاستفادة من القرآن الكريم في تكوين رؤية نظرية. يشير الباحث إلى أن الرؤية المنهجية لكيفية قراءة القرآن أسيرة منهجين الأول التفسير الدلالي لألفاظ الآيات والثاني التفسير الموضوعي الذي يأخذ بعين الاعتبار مجموع برئي الآيات ذات العلاقة بموضوع واحد. وكلاهما منهج بجزيئي. ويقترح بديلا ثالثا عن هذين المنهجين ينظر إلى القرآن الكريم باعتباره بنية معرفية متماسكة، ويقرأ القرآن كله، وينظر إلى أي آية أو موضوع في ضوء الوحدة البنائية لكامل القرآن. وهذا المنهج الثالث يستفيد من مناهج التأويل والتفسير البياني والموضوعي والتفسير بالمأثور وغيرها، ولكن عين المفسر تبقى متوجهة إلى المقاصد الكلية للدين. وتكون هذه المقاصد الكلية كما

$$
\begin{aligned}
& 57 \text { الريسوني، أمد. الفكر المقاصدي: قواعده وفوائده. الدار البيضاء: سبريس 1999. (سلسلة كتاب الجيب رقم } 9 \text { التي تصدر عن }
\end{aligned}
$$

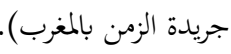

$$
\begin{aligned}
& 58 \\
& 59 \\
& \text { جابر، حسن. المثقف الإسلامي بين الفقيه وإشكالية المنهج. مجلة الوعي المعاصر . السنة الأولى، العددان } 4 \text { و5 شتاء 2000، ص6- }
\end{aligned}
$$


يهدي إليها القرآن الكريم هي الحاكمة لأي نظرة أخرى وللتعامل مع أي نص أو رواية أو أثر. لقد درج الفقهاء في المنهج الاستقرائي التجزيئي على استنباط الأحكام الفقهية وتعميم ذلك للوصول إلى رؤية كلية. هذا النوع من التأسيس المنهجي سبق أن أكّد عليه بقوة طه جابر العلواني في دعوته إلى تطوير منهجية للتعامل مع القرآن الكريم، تقوم على مبدأ الوحدة البنائية في القرآن الكريم في بموعه. صحيح أن الآية الواحدة في السورة هي واحدة من واحدات السورة، يمكن أن تقوم بذاتما وبما جاورها من الآيات، وأن السورة هي واحدة من واحدات القرآن يمكن أن تقوم بذاتما وبما جاورها... إلا أن استنباط الحكم الشرعي والوصول إلى مقاصد الدين في أي مسألة من المسائل لا يمكن أن يتم على الوجه الأكمل إلا بأخذ القرآن جملة واحدة وملاحظة وحدته البنائية؛ فثمة "وحدة بنائية على مستوى الآية والسورة ومستوى القرآن كله.. وفي تراثنا لا نجد لهذه الوحدة أثرا كبيرا."61 والإشارات التي نجدها عند ابن هشام أو عند أبي علي الفارسي أو عند الحارث المحاسبي أو عند الأصوليين في دائرة الأحكام يفهمها العلواني بوصفها إشارات إلى الوحدة

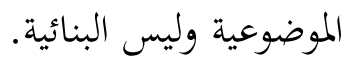

وينتقد المتحفظون علمشروع إسلامية المعرفة اهتمامه الكبير بقضية المنهجية، ونكتفي هنا بالإشارة إلى موقفين من مواقف هؤلاء المتحفظين لعلاقتهما المباشرة بأهمية البحث في المنهجية، وباعتبار هذا النقد يتوجه من داخل الدائرة الإسلامية، أما البحث التفصيلي في مناقشة المواقف الأخرى فله مقام آخر. 62

الموقف الأول هو موقف فضل الرحمن، الذي يبني موقفه من إسلامية المعرفة على أساس فهمه لمنهج التفكير الإنساني ولكيفية حدوث المعرفة عند الإنسان؛ فهو يرى أغا تتم بطريقة غامضة لا سبيل إلى معرفتها. والطرق التي يذكرها بعض الفلاسفة حول إنتاج المعرفة ما هي إلا اجتهادات في الوصف لا تحدث في عالم الواقع، وأنّ الأفضل استثمار الوقت في إيجاد المفكرين، وليس في الكيفية التي عليهم أن يفكروا بها، وأنّ الأولى هو إيجاد العقول وليس كيفية عملها. والمطلوب على أية حال علماء ومفكرون قادرون على التحليل الناقد لتراث المسلمين والتراث الغربي في آن واحد. وينبع تركيز الأهمية على العلماء وليس على العلم 61 61 العلواني، طه جابر. إصلاح الفكر الإسلامي: مدخل إلى نظم الحطاب. عمان، الأردن: المعهد العلمي للفكر الإسلامي، 1995، ص107. ملكاوي، فتحي. حوارات إسلامية المعرفة. بحلة إسلامية المعرفة. السنة السابعة، العدد 26، صيف 2001م، ص99-135. 
نفسه من أنه لا توجد طريقة ميكانيكية لأسلمة العلم. وعندما يتمكن من الإنسان الاتحاه الذي يريد القرآن زرعه فيه فإن مرحلة إنتاج المعرفة ستتحقق، وعندها يتمكن الإنسان من تقدير تراثه وتراث الغرب وتقويمهما. 63 ولا خلاف على أن أسلمة المعرفة تتطلب منهجية في التفكير تتمثل في القدرة على التحليل الناقد لتراث المسلمين التاريخي وتراث الغربيين المعاصر. وأن هذه القدرة يجب أن تتوافر في العلماء المسلمين المعاصرين. ولذلك يلزم تدريب العلماء المسلمين المعاصرين على هذه المنهجية لاكتساب مهارات التفكير التحليلي الناقد الذي يتصف بالاستقلالية والإبداع، وأنّ أيّة تفاصيل في مشروع أسلمة المعرفة لا تتجاوز تدريب العقل المسلم على امتلاك القدرة النقدية والإبداعية.

ومن المنطقي أن يدعو فضل الرحمن إلى استثمار الوقت والمال والجههد والإمكانات في أسلمة العلماء وليس العلم، باعتبار أن العلماء هم الذي ينتجون العلم. ذلك أن المفكرين هم الذين ينتجون الفكر، ولا معنى لهذا كله إذا لم يتم إنتاج الفكر المطلوب، الجيد، المفيد، وكيف نستطيع إنتاج هذا الفكر إذا لم يتعلم المفكر المعايير الصحيحة للفكر المطلوب ومنهجية الوصول إليه؟ كذلك فإن العقول ليست "أشياء" يمكن أن تُصبّ في قوالب محددة، وإنما هي قدرات يجري تفعيلها وإعمالها في اتحاهات مختلفة، ونريد لها اختيار ابتحاهات محددة دون غيرها.

من المنطقي إذن قبل عملية أسلمة العلماء وفي أثناء هذه العملية توصيف المنهجية التي يمكن بواسطتها أن يتحقق هذا الهدف، وذلك بتدريب العلماء على إنتاج العلوم والمعارف ضمن إطار متناغم مع مبادئ الإسلام ومقاصده سواء في منهج التثبيت والتوثيق والاجتهاد في الإتقان والإحسان أو في طريقة التعبير عن هذه المعارف وصياغتها باستدخال أبعاد الشهود والغيب والنسبي والمطلق والكون والوحي، أو في طريقة توظيف هذه المعارف والعلوم لخدمة الناس وتيسير سبل حياتم.

63 Rahman, Fazlur. Islamization of Knowledge: A Response. American Journal of Islamic Social Sciences AJISS, 5(1) 1988. p. 3-11. 
أما الموقف الثاني فهو موقف محمد سعيد رمضان البوطي. ومع أن البوطي 64 لا يعارض في ضروة المنهجية وأهمية التفكير المنهجي باعتبار أن السير في طريق المعرفة وتغذية العقل الإنساني يحتاج إلى ترتيب معين في الخطى وقطع المراحل، الأمر الذي يقتضي ضرورة التزام نظام معين يسميه منهج المعرفة، فإن قضية المنهجية عنده ليست قضية في الفكر الإسلامي المعاصر، باعتبار أن "المنهج حقيقة ثابتة وليس عملا إبداعيا"، وأنه ليس أكثر من ميزان له "حقيقة ذات وجود خارجي ثابت يخضع للدراية والاكتشاف، شأنه كشأن أي من الموجودات المادية الثابتة بحدّ ذاتا.. ولا يخضع لأي تطوير فكري أو جهد إبداعي"؛ إذ لو احتاج إلى ذلك، فإنه يلزمه منهج وميزان يضبطه، ونقع في محذور التسلسل اللاهائي للمناهج، وهو عيب لا يستقيم معه تفكير.

ومع ذلك فإن البوطي يؤكد أن علماء المسلمين كانوا في حاجة ماسة إلى المنطق الأرسطوطاليسي وأنه: "من الثابت يقينا أن السعي إلى دراسة منهج شامل للمعرفة، في أي عصر من العصور، لا يككن أن يتم بمنأى عن المنطق اليوناني، والتعرف عليه ودراسته دراسة متعمقة مستوعبة." والأهم من ذلك أن البوطي لا يرى للفكر الإسلامي المعاصر دورا في اكتشاف ذلك المنهج الثابت، لأن "المنهج موجود، وإن عصر الإسلام الذهبي قد شهد تكامل بنيانه على أيدي المسلمين اكتشافا وتنسيقا وتدوينا.. من خلال سعيهم إلى التوفيق بين مدرستي الحديث في الحجاز والرأي في العراق، حيث دونوا مناهج تفسير النصوص وأصول الاجتهاد لمعرفة الأحكام، كما رسخوا القوانين المتكفلة بالتفريق بين الحقائق التي لا يصح تلقيها إلا عقلا والتي لا يمكن تلقيها إلا نقلا."

أما المطلوب من علماء الأمة في هذا العصر فيما يتعلق بالمنهج فإنه لا يتجاوز "إعادة التنسيق بين فروعه وأجزائه المتنوعة على نحو يتفق مع حاجاتنا الراهنة.. والتقاط ما تلحّ الحاجة الشديدة إليه من مجموع

البوطي. سعيد رمضان. أزمة المعرفة وعلاجها في حياتنا الفكرية المعاصرة. في: المنهجية الإسلامية. مرجع سابق. مجلد رقم 1، ص55- 
فصول ذلك المنهج وجوانبه الكلية المتكاملة، ثم إبرازه بلغة العصر وتبسيطه قدر الاستطاعة، ثم طرحه في ساحات الدعوة الإسلامية ليسير الحوار الإسلامي على ضوئه وينضبط بهديه."65

أما المطلوب من أجل السعي للوصول إلى منهج سديد للمعرفة الحرة فهو تحرير العقل من غوائل النفس وأهوائها، فالحرية الحقيقية التي يدعيها العالم الغربي لا يمكن أن تتحقق إلا عندما يتمتع الإنسان بقدرة ذاتية كافية تمكنه من إقصاء رغباته وأهوائه النفسية، والركون إلى صوت العقل صافيا عن الشوائب، وأن ذلك لا يتحقق إلا بقدر كبير من المعاناة التربوية والتحرير الوجداني. وما بعث الله الرسل والأنبياء إلا ليُعبّدوا طريق المعرفة والعلم أمام العقل وعليه فإن "التزكية النفسية هي بوابة المنهج إلى المعرفة."66

وهكذا يرفع الشيخ البوطي شعار أسلمة النفس بدلا من أسلمة المعرفة. والشيخ البوطي عالم فقيه معروف له مكانته الرفيعة في بلده وعلى مستوى كثير من قطاعات الأمة، ونظراته الفكرية فضلا عن الفقهية مسجلة في الكثير من إنتاجه الغزير الذي امتد على مدى نصف القرن الماضي، لكن رؤيته هذه تنتاجها ثغرات عديدة. فالمنهج الذي يتحدث عنه ويضرب عليه مثالا هو طريقة فهم النص القرآني (منهج التفسير) وطريقة الاجتهاد في استنباط الأحكام من أدلتها (منهج أصول الفقه) ليس له وجود طبيعي ثابت مثل ثبات الأشياء المادية الموجودة في الخارج بلا تغيير. فالمفسرون عبر التاريخ الإسلامي شكلوا مناهج متنوعة لا منهجا واحدا "مناهج المفسرين". أما أصول الفقه فلا شك في أنه كان سيد المنهج والتفكير المنهجي في التاريخ الإسلامي. لكن منهج أصول الفقه لم يكتشف ويدوّن ويضبط مرة واحدة، بل إنه اعتمد أساسا على منهج القياس لفترة طويلة. ثم طور العلماء مفاهيم وأدوات وآليات كان منها الإجماع والاستحسان والاستصحاب وسد الذريعة والمصالح المرسلة، وغير ذلك إلى أن تطور مفهوم المقاصد، وقد رافق ذلك تقعيد القواعد الفقهية والأصولية ثم ابته البحث نحو تقعيد قواعد المقاصد. وهل كان ذلك إلا تطويرا وتغييرا في المنهج؟ ثم إن المدارس الفكرية في تاريخ الإسلام القديم والحديث تنوعت وتعددت في مناهج النظر والتفكير والبحث والاجتهاد؛ فثمة مناهج للمتكلمين ومناهج للفقهاء والأصوليين ومناهج للمتصوفة وأهل العرفان ومناهج للفلاسفة ومناهج للعلماء الطبيعيين في الكيمياء والفيزياء والطب والفلك.. إلخ، ولكل مدرسة من هذه المدارس فروعها.

$$
65 \text { } 65
$$


وتلتقي هذه المدارس الفكرية جميعها، كما تلتقي تطبيقات مناهج البحث والنظر في هذه المدارس داخل فروع التخصص المختلفة، على أسس مشتركة بتعل منها مدارس فكرية إسلامية وبحمعها ملامح موحدة للمنهج الإسلامي، وتميز تلك الأسس المشتركة وهذه الملامح الموحدة هذا المنهج الإسلامي العام عن أي منهج غير إسلامي، ومع ذلك فإن ثمة فروقا بين مناهج الأشاعرة والمعتزلة لا يستهان بها. ومثل هذه الفروق وربما أكثر أهمية منها نجده بين مناهج المتكلمين من أمثال أبي الحسن الأشعري والأشاعرة والنظام من المعتزلة من جهة ومناهج فلاسفة الإسلام من أمثال الفارابي وابن سينا من جهة أخرى. ونستطيع أن نتوسع في استخدام مفهوم المنهج ودلالاته وتطبيقاته في داخل الميدان المعرفي الوحد، الأمر الذي ميز بين مناهج الفقهاء في المدرسة السنية مثل أبي حنيفة وأحمد مثلا، وبين مناهج تصحيح الحديث عند كل من البخاري ومسلم.

وإذا أردنا تضييق مفهوم المنهج لنتحدث فقط عن العناصر الكلية والمشتركة لطريقة التفكير والبحث والتعامل مع المصادر وتنزيل الأحكام على الوقائع وتطبيقها على المواقف والقضايا، وصح عندنا أن نتحدث عن المنهج الإسلامي أو منهج الإسلام، فإننا لا بد أن نميز هذا المنهج عن ذلك المنهج الذي يستخدمه العلماء والباحثون من أهل الثقافات أو الحضارات أو الأديان الأخرى. أليس ذلك -على الأقل - وجها من وجوه الفهم لقوله سبحانه "لكل جعلنا منكم شرعة ومنهاجا، ولو شاء الله لجعلكم أمة واحدة" (المائدة:

ولعلّ الشيخ البوطي يريد أن يكصر مفهوم المنهج أكثر من ذلك في البدهيات والمسلمات التي تلتقي عندها العقول السليمة والطبائع النقية، مثل حقائق الحساب والأسماء والصفات التي تقاس بالحساب والميزان. ولكن متى كانت مثل هذه البدهيات عِلْما يصف طريقة تفكير الفئات المختلفة من الناس وطريقة فهمهم لمصادر المعرفة وتعاملهم معها من أجل استنباط الأحكام أو تحديد قواعد السلوك؟! إن اتفاق الناس على صحة بعض البدهيات في قرارة أنفسهم لا يعني بالضرورة أن يسلكوا في حياتم ومواقفهم وفقها، كآيات الله المبصرة عندما جاءت فرعون وقومه استيقتها أنفسهم لكنهم جحدوا بها ظلما وعلوا. "فلمّا جاءقم آياتُنا 
مبصرة قالوا هذا سحرُ مبين، وجحدُوا بها واستْقتنتها أنفسهم ظلما وعُلوّا، فانظر كيف كان عاقبة المفسدين". (النمل 13-14) - (14)

إن دلالة المنهج تكون غير ذات معنى لو اقتصرت على العقل المجرد بصورته المثالية، الذي يصفه الشيخ البوطي ويعبر عنه بالميزان. فهذا العقل - الميزان مقياسُ تقاس إليه الأمور وتوزن به مقاديرها. ويمكن على أساسه أن يصنّف البشر إلى أصحاب العقول السليمة الذين يستيقنون كل الأمور الصحيحة وينتهجون دائما وفق ما تقتضيه والفئة الثانية فئة الذين لا ينهجون وفق مقتضى الحق.

وحتى في هذه الحالة فإننا نستطيع أن نتحدث عن منهجين على الأقل، إذ لا معنى للمنهج إذا لم يكن وصفا لطريقة تفكير فئة من الناس وطريقة سلوكهم.

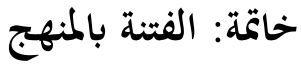

يبدو أن مصطلح المنهج/المنهجية أو المنهاج/المنهاجية، لا يخلو من جاذبية وسحر في بيان أصحاب البيان، سواء منهم من كان في مجال التذوق الأدبي، أو التنافس الأيديولوجي أو الوعظ الوجداني أو التبشير الدعوي، أو الادعاء العلمي.. فكل هؤلاء يتوسل بلمنهجية ويدعي وصلا بها، ويقارع بمنهجه مناهج الآخرين ممن يدّعون المنهجية في التفكير أو في القول أو العمل، أو ممن يدّعى عليهم فقداها.

فعلى الصعيد الأكاديمي مثلا في دوائر البحث في الجامعات ولدى العديد من الشخصيات التي ظهرت في نصف القرن الماضي مثلا بوصفها من أصحاب المشروعات الفكرية المتميزة نجد من يحاول تخليص منهجية الفكر العربي الإسلامي مما لحق به من الأفكار المسبقة الخاطئة عبر التاريخ (حسن عبد الحميد عبد الرممن) وبعضهم يحاول أن يفسر بالمنهج الأصولي القائم على الاستقراء ازدهار الحضارة الإسلامية وتميزها (علي سامي النشار). وبعضهم يحاول أن يفسر سبب تدهور الحضارة الإسلامية بسبب المنهج الفقهي الذي تحكم في العقل العربي (الإسلامي)، ففقد هذا العقل قدرته العبقرية وتوقف عن الإبداع (محمد عابد الجابري). وبعضهم يحاول إعادة عرض هذا العلم على أنه وضع قواعد ومعايير لتفسير النصوص الدينية، وبالتالي فإن أصول الفقه هو نظرية في التفسير وهو بهذا الاعتبار نسق مقفل! (حسن حنفي). 
وييدو أن ثمّة اتفاقا على أن قضية المنهجية في الفكر الإسلامي قضية على غاية من الأهمية، سواء كانت منهجية في التفكير، أو في البحث للوصول إلى المعرفة واختبارها وتوظيفها، أو في التعامل مع مصادر الإسلام التأسيسية وأصوله وفي التعامل مع التراث الإسلامي والتراث الإنساني أو في التفاعل مع واقع الأمة المعاصر أو واقع العالم المعاصر.

ولا شك في أن المنهجية في المنظور الإسلامي -مثلها في ذلك مثل سائر المسائل الأخرى- تستند إلى أصول وقواعد تتصف بالاستقرار والثبات، وبعض عناصرها متغيّر يتطوّر تبعا لخبرة العلماء واجتهاداقم، وبما يستقر من أعراف لدى جماعة العلماء في بجال من المجالات المعرفية أو في جيل من الأجيال. ويتشكل بعض هذه العناصر بتأثير طبيعة القضايا والمشكلات التي هي موضوع البحث، أو بما يفتح الله به على آحاد العلماء، أو بتأثير تفاعل أبناء الأمة مع النوازل والمستجدات من المسائل والأحداث.

والمنهجية في النهاية اجتهاد بشري، يلحقه الصواب والخطأ؛ وبالتالي فإن الحاجة للبحث في المنهجية والتفكير المنهجي تبقى قائمة لتفعيل أوجه الصواب وتصويب أوجه الخطأ، وعلى كل جيل أن يجتهد فيبذل جهده وييدّد فهمه ورؤيته، ويبدع في دفع حدود المعرفة إلى آفاق جديدة، يستلهم فيها مقاصد الحق من الخلق، ويظلّ الطريق مفتوحا لمن يأتي بعده.

لكن هذا الاجتهاد لا يزال يعدّ مغامرة أو مخاطرة، بسبب ما يسود أجواء الأمة من "الغوغائية العلمية" أو "الغوغائية الشعبية"، لذلك لا يلِجُ ميدانه إلاّ أولو العزم من أهل العلم، وبقدر من التهيب والحياء، وهو أمر يدعو إلى القلق، لكن القلق الأشد هو الناتج عن ممارسات كثير ممن فُنْنُوا بالمنهج وفتنوا به بعض الحلق، وشقوا لهم - سي غمرة الاضطراب والغموض المنهجي- مناهج روجوا فيها لشعارات قد لا تكون مأمونة العواقب رغم أخها في أصلها كلمات حق! وإذا كان ميدان البحث في المنهجية قد شهد ألوانا من البيان الخطابي والتوصيف النظري، فإنّا نأمل أن تتوجه جهود العلماء والباحثين للانتقال إلى مرحلة البيان المنهجي والممارسة المنهجية، وهذه من غير شك مسؤولية كبيرة وخطيرة، لكن ذلك لا يرفع عن آحاد الناس مسؤوليتهم في تتبع مسالك الفهم وسبل النظر ومناهج الفكر، وذلك من أجل التبصر في أمورهم الخاصة والعامة والاستبراء لدينهم في دنياهم وأخراهم، 
والذين يعلمون درجات، كلها فوق الذين لا يعلمون، والعلم كسب، ولكلٍ كسبه منه وسعيه فيه، وإذا لزمت إدانة الغوغائية في المنهج حيث يسود الجهل والهوى، فبمثلها تدان الصفوية والفئوية التي تعزل أهل العلم والمنهج، وتجعل فهمهم منزلة يتجاوز الوصول إليها حد الإمكان! 